\title{
LA URBANÍSTICA MODERNA. EL SEGLE DELS TRAÇATS
}

Miquel COROMINAS AYALA

La industrialització de finals del segle XVIII i del segle XIX es produeix fonamentalment a les ciutats. Com que no podran albergar l'allau migratori en els vells i antiquats cascs urbans serà necessària una nova forma urbana capaç d'acolli aquestes creixements. Les estratègies es basaran en nous traçats urbans de gran superfície amb uns carrers moderns, amples, ben anivellats, amb serveis i transpor col-lectiu i grans mançanes amb un parcel-lari molt regular, capaç d'absorbir les industries i els nous tipus residencials.

Trobarem tres tipus de traçat: Les avingudes, els "rings" o rondes i els eixamples. Tots tenen en comú la utilització d'una retícula geomètrica de gran regularitat. De tots ells els eixamples són els més significatius i el millor exponent de la ciuta industrial. Aquests teixits basats en traçats viaris són segurament els teixits urban de major interès urbanístic projectats en els darrers 200 anys i els que millor representen el conjunt de paradigmes de l'urbanisme contemporani: densitat, compacitat, barreja d'usos i flexibilitat, i per tant gaudeixen d'un gran valor patrimonial, econòmic i social.

Traçats, eixamples, avingudes, rondes

\section{MODERN URBAN PLANNING: URBAN LAYOUT'S CENTURY}

The industrialization in the end of 18th century and the beginning of 19th takes place in the cities. As they are not able to house the immigration wave in the old town premises, a new urban form will be needed. The strategies will focus in new urban layouts, of a great area, with wide modern streets, well leveled, with service infrastructure and mass transportation and great blocks with a very regular division that can host the industries and the new residential typologies.

We will find three kinds of urban layouts: avenues, rings-roads and extensions. All of them have in common the use of a very regular geometric grid. Among them, the extensions are the most significant ones and the best exponent of the industrial city. These plans, based on roads layouts, are the most interesting urban projects from the last 200 years and the ones that better represent the set of paradigms of the contemporary urbanism: density, compactness, mix of uses and flexibility, and so far enjoy a great value as social and economic heritage.

Urban layouts, extensions, avenues and ring-roads

\section{INTRODUCCIÓ}

\section{La ciutat}

La ciutat com a forma social és inherent a pràcticament totes les civilitzacions. Gairebé totes les cultures n'han fundat, en funden i en fundaran. Alguna de les ciutats més antigues com Erbil, a l'Iran, ja tenen força mil.lennis a les seves pedres.

No només ha estat objecte d'interès en el món antic. Cada cop més la població urbana mundial va en augment en detriment del món rural. Avui en dia (2011) dels 7.000 milions d'habitants de la terra més del 50\% de la població mundial ja viu en ciutats i la previsió és que el 2030 sigui el 60\%.

Durant el segle XIX la ciutat té una evolució molt important. El seu gran creixement, les preocupants condicions de vida, els problemes derivats de la higiene, els continus avenços tecnològics i la posada en pràctica de nombroses aportacions fa que tingui una transformació com mai havia experimentat en tota la seva història anterior. És una transformació en extensió en superfície, però sobretot en població. La ciutat i les condicions de vida de la població esdevindran objecte d'estudi. De l'estudi de la ciutat i les seves característiques sorgirà una nova disciplina: la Urbanística.

\section{La Urbanística}

La Urbanística és per tant una ciència recent que té els seus inicis en la reflexió sobre la ciutat moderna del segle XIX. La disciplina comença a formar-se a la segona meitat del segle XIX, època en la qual les memòries del plans comencen a teoritzar sobre la ciutat moderna ${ }^{2}$. És publicaran els primers manuals sobre la construcció de la ciutat ${ }^{3}$. Els primers cursos d'urbanisme s'impartiran simultàniament el 1909 a l'Escola de Cívic Art de Liverpool al Regne Unit i a la Universitat de Harvard als Estats Units.

L'objectiu principal d'aquest treball és l'estudi de la producció massiva de ciutat que es realitza principalment entre els inicis del segle XIX que és quant apareix la veritable ciutat moderna i finals del segle XX quant les grans ciutats de

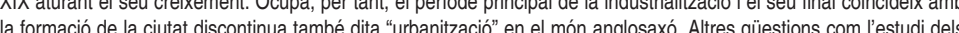
.

3 Tradicionalment els primers manuals moderns considerats eren d'origen alemany: Baumeister (1876) i Stübben (1890). Avui dia els treballs de Cerdà, força anteriors és poden considerar com els primers manuals atesa la profunda reflexió que Cerdà planteja en el projecte per Barcelona. 


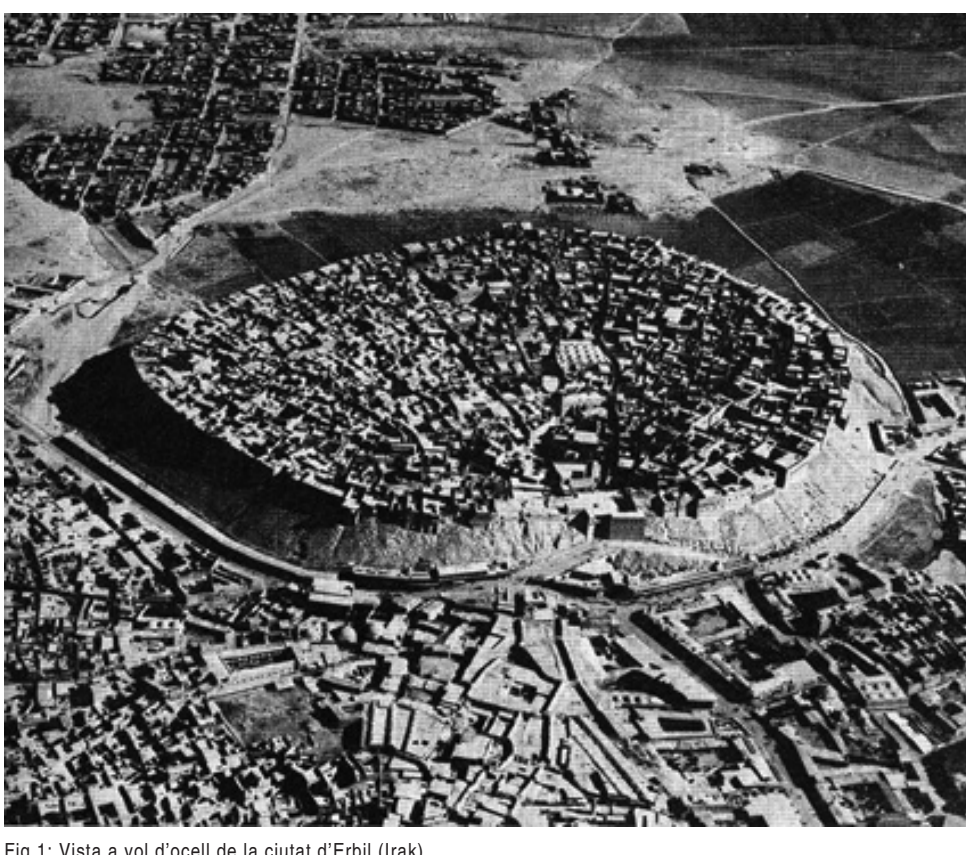

Fig. 1: Vista a vol d'ocell de la ciutat d'Erbil (lrak).

Un dels aspectes importants de la urbanística és el Survey: estudi analític de la forma, dels elements, de la historia, la població, les condicions socioeconòmiques, de la ciutat i el territori. Aquesta informació urbanística permet entendre, realitzar diagnosi i proposar projectes ben argumentats.

\section{La forma urbana}

Una de les constants de la ciutat és que es reconeix una forma urbana específica de cada cultura la qual cosa les fa molt interessants com dipositàries de cada forma de civilització. Les ciutats són la màxima expressió de cada civilització. Les ciutats dels ibers, grecs, romans, les ciutats medievals, renaixentistes, tenen unes formes molt significatives de cada període i força diferents entre si, que les fan molt facilment reconeixibles.

\section{El lloc i els patrons}

Cada cultura ha desenvolupat un tipus de ciutat, i el més interesant és que en moltes ocasions la ciutat ha estat construïda sota un patró o una manera de fer comuna. El rigor en la tria de l'emplaçament en la fundació de la ciutat grega, la consistència del traçat de la ciutat romana o la qualitat de l'espai a la ciutat del renaixement ho exemplifiquen.
De vegades, la ciutat és construïa sota lleis o codis que determinaven la seva forma com és el cas de les ciutats espanyoles fundades a centre i sud-América a partir de la promulgació de les "Ordenanzas de nueva población" per Felip II el 1573, a partir de l'experiència de gairebé un segle de fundacions prèvies a Espanya ${ }^{4}$ i Amèrica.

\section{Evolució}

La ciutat, excepte en el període medieval ${ }^{5}$, ha tingut una clara evolució en la seva forma urbana i molt especialment en els seus elements bàsics i en els teixits urbans resultants. Aquest desenvolupament ha estat lent i força dilatat en el temps. Cada període ha durat varis segles i per tant podem trobar ciutats o fragments molt significatius de cada moment.

\section{El pla o projecte}

La ciutat ha tingut en alguns casos una generació espontània i ha sorgit a partir d'un abric marítim, una fortalesa, un encreuament de camins... Però també en força casos la ciutat, o una part important d'ella, ha estat el resultat d'un pla o projecte resultat d'un treball intel-lectual raonat que s'ha portat a la pràctica sobre el terreny amb un gran esforç col-lectiu. Aquest projecte ha creat una trama urbana específica amb un clar ordre geomètric $i$ amb un alt nivell de racionalitat. Aquestes projectes han significat una evolució i un avanç cap a noves formes d'ordenació de l'espai urbà, i per tant de la ciutat en el seu conjunt. Les ciutats de fundació americanes o els projectes d'eixample del XIX en són un bon exemple.

\section{La ciutat preindustrial}

La ciutat al llarg de la història i fins al final del segle XVIII ha tingut un creixement lent i una dimensió reduïda, amb l'excepció de Roma, que va arribar a una població estimada d'un milió d'habitants, tot i que és un valor molt elevat si considerem la superfície que ocupava. La ciutat ha estat generalment emmurallada fins força avançat el segle XIX, amb l'excepció de les colònies o ciutats de fundació que és plantejaven en molts casos com a ciutats obertes.

Els canvis més significatius a la ciutat s'iniciaran al segle XIX amb el gran creixement que suposarà la industrialització. L'energia és produirà a les ciutats, prop del lloc de mercat i transport, i això suposarà un transvasament de

4 La fundació de "Campamenti" el 1483, avui Santa Fe a Granada, per preparar l'assalt a l'Allhambra sés un magnific referent. 5 El període medieval presenta un clar retrocés social i, per tant, urbà. Tot i això, en aquest període algunes ciutats realitzaran intervencions importants com és el cas de la Plaça del Campo a Siena (La pavimentació actual de totxo I
traverti és de 1349). 
la població del camp cap la ciutat, i una substitució del treball agrícola per l'industrial. Algunes ciutats com Londres tindran un creixement de més del $600 \%$ al llarg del segle XIX ${ }^{6}$.

\section{Quadrícules i malles}

Amb anterioritat als eixamples del XIX hi ha tota una tradició d'ordenació del sòl del territori i de les ciutats amb un suport de base geomètrica regular: les quadrícules. Grecs, romans, espanyols, nord-americans, xinesos les han utilitzat com a sistema de colonització del territori. L’objectiu principal d'aquestes quadrícules era delimitar i distribuir el sòl pels nous colons. Per tant és tractava d'ordenacions de sòl amb una reserva d'accés, normalment uns carrers o camins força estrets.

A la ciutat grega els carrers principals tenien 7 metres d'ample i els secundaris $4 \mathrm{~m}$. A la ciutat romana de Pompeia, entre 8 i $10 \mathrm{~m}$ d'ample a les vies principals i entre 3,5 i 5,5 m a les secundàries. A Santa Fe a Granada (1483 i 1491) l'ample dels carrers era de 10 peus castellans $(2,786 \mathrm{~m})$. A les ciutats de fundació a sud-América els carrers feien entre 10 i 12 vares castellanes (entre 8,35 i 10,02 metres d'ample).

A nivell territorial i en el cas de les centúries romanes, l'ample dels camins era de 40 i 20 peus romans en el Decumanus i el Cardus màxims (11,84 i 5,92 m) i 12 i 8 peus romans per les altres vies (3,55 i 2,57 m respectivament) En el cas dels EEUU la Land Ordinance de 1785, determinarà una nova geometria del territori al dividir-se en unitats quadrades les "Townships" de 6 per 6 milles que a la vegada és subdividien en trenta sis unitats d'una milla quadrada.

Als Eixamples de la ciutat industrial el que pren força és la xarxa viària. É carrers són molt més amples, en general de 18 a 30 m d'ample per a les vies ordinàries. Els carrers no nomes són més amples, estan més ben traçats, són més regulars i estan ordenats segons una precisa retícula ortogonal. Són un carrers moderns: rectes, ben anivellats i donen suport de serveis en superfície i en el subsòl, i tenen capacitat per acollir el transport col-lectiu. És tracta d'uns carrers especialitzats de dos plans diferents: calçades per a vehicles a nivell inferior, unes àmplies voreres elevades pels vianants i per separar els vorals i l'arbrat. Aquests carrers tenen poc a veure amb els de la ciutat anterior. Segurament les voreres dels eixamples constitueixen un dels espais socials més generalitzat i interesant de la nova forma urbana. Passem d'un conjun de carrers a una potent xarxa viària. Com a resultat tenim un creixemen il.limitat en el territori. Els eixamples és convertiran en la forma urbana més característica de la ciutat industrial.
A les quadrícules les entrevies o mançanes tendeixen a ser grans o molt grans. En canvi als eixamples les mançanes no són en general massa grans. La diferència entre el teixit resultant de les quadrícules i les malles o eixamples és la diferent proporció que els diferents teixits dediquen als carrers, o elements servidors, com diria L. Kahn. Mentre que a les quadrícules l'espai destinat a l'accés ocupa una proporció baixa (10-15\% del sòl), concretament el $12 \%$ a Caracas (150_10 vares, mançana/carrer), el 14\% a Buenos Aires (140_11 vares) o el 15\% a Santiago (138 12 vares), als eixamples la proporció és força més alta (30-35\% del sòl), $-30 \%$ en el cas de l'Eixample de Barcelona o 32-34\% en el cas de Manhattan-. Aquest valor no significa res més que la capacitat de donar servei des del viari, que és un dels atributs principals dels eixamples.

En el procés de modernització de les ciutats amb quadrícules s'han produï dos tipus d'intervenció: eixamplament dels carrers (Buenos Aires) o la fragmentació de mançanes de dimensions desproporcionades (Philadelphia). El antics camins i carrers de les velles quadrícules de l'època colonial seran ampliats, regularitzats i incorporaran voreres a la secció la qual cosa afavorirà la confusió entre les quadrícules i els eixamples. El parcel-lari tindrà però una major persistència així com la manera d'edificar, molt més extensiva en les quadrícules que en els eixamples pel que fa a l'ocupació del sòl a l' interior de les mançanes. Les ciutats amb trames d'eixample del XIX no han hagut de realitzar intervencions radicals sobre els carrers o les mançanes. A les quadrícules es valora el sòl de les mançanes mentre que als eixamples és valora el vial, la façana i el front edificat.

\section{LA CIUTAT INDUSTRIAL}

\section{El canvi tecnològic}

La ciutat del XIX és la síntesi de tots uns canvis que transformaran la nostra societat. Són canvis que de la mà de la industrialització, si seguim la historiografia clàssica d'arrel anglòfila, ens portaran a una nova manera de fer o refer la ciutat. Hi haurà canvis en el model de producció, passant del trebal artesanal individual gairebé manual a les grans concentracions industrials i a la producció en cadena. La ciutat començarà a especialitzar-se i es requeriran mitjans de transport per mobilitzar la nova classe treballadora.

\section{La nova casa burgesa}

La casa artesanal de caràcter individual que recull en un modest immoble l'habitatge i el taller de treball en planta baixa serà substituïda per edificis burgesos de gran alçària d'habitatges plurifamiliars de lloguer on la planta baixa es destinarà a usos comercials preferentment. 

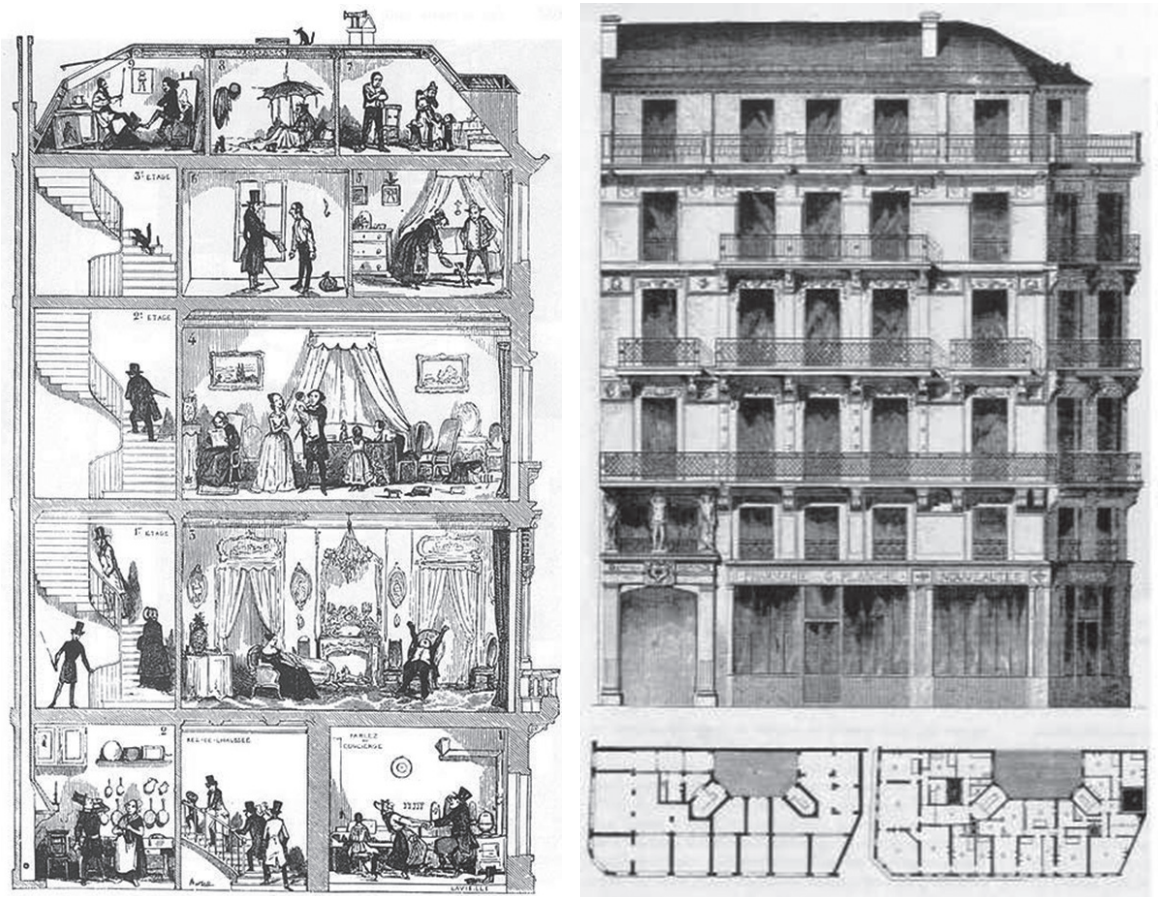

Fig.2: Edificis burgesos a París

Els nous sistemes de transport com el ferrocarril modificaran totes les relacions territorials. A la ciutat s'incorporarà en forma de transport quotidià col-lectiu. El creixement de la ciutat estarà supeditat a aquest sistema de transport. Els canvis també vindran del món de les telecomunicacions, la higiene, etc. Probablement els canvis en la societat i la ciutat del XIX són els més substancials que ha tingut la ciutat en la seva història fins ara.

\section{Les opcions del creixement urbà}

La ciutat del XIX, en la major part del casos encara emmurallada, davant dels nous canvis tecnològics tindrà dues opcions: l'extensió urbana un cop superades les muralles o la reforma i creixement intern dels nuclis importants amb recintes emmurallats recents.

Dins els casos paradigmàtics d'extensió trobem el Pla de Manhattan de 1811 pel seu caràcter pioner i l'Eixample de Barcelona de 1859 pel seu valor teòric, projectual i el seu excel·lent desenvolupament.

Dins els casos paradigmàtics de reforma i/o extensió urbana els més significatius són la Reforma i extensió de París desenvolupada sota el tercer imperi pel
Baró Haussman entre 1853 i 1870, la urbanització de les avingudes a Lisboa iniciat el 1879, i els projectes del Ring de Viena iniciat el 1858 i de Colònia iniciat el 1881.

Es tracta de casos que poden representar molt bé la urbanística moderna iniciada al segle XIX.

\section{EL SEGLE DELS TRAÇATS}

Durant el segle XIX s'inicia una nova manera de fer ciutat que s'estendrà fins els inicis del segle XX. És tracte d'una forma urbana que té com element comú un "traçat" d'important dimensió amb una precisa i regular geometria de suport. El traçat de les ciutats es planteja sota tres models formals:

- Geometries reticulars de base ortogonal com els "eixamples".

Geometries lineals o d'avingudes.

Geometries anulars o de rondes com els "rings".

L'excel-lent traçat i la gran amplada dels nous carrers, avingudes i bulevards, donaran una gran capacitat al nou teixit urbà. La llum i el sol ompliran la ciutat. Amb els serveis d'abastament d'aigües, el nou i modern clavegueram i els nous tipus d'habitatges es produirà una ciutat higiènica com mai s'havia conegut. La nova forma urbana serà un èxit en aquelles ciutats que l'adoptin.

\subsection{Els Eixamples del XIX}

\section{Una forma innovadora}

Els eixamples són fonamentalment estructura, infraestructura i serveis davan el repartiment de sòl de la ciutat colonial. Es redimensionaran els carrers es reduiran les mides de la mançana. El viari tindrà una alta proporció en el teixit resultant. Només amb aquests canvis resultarà una forma urbana totalment nova.

\section{Dos projectes pioners}

Entre el nombrós conjunt d'eixamples projectat al segle XIX hi ha dos eixamples que destaquen sobre els altres. Un ple d'intuïció, l'Eixample de Manhattan de 1811, treball del cartògraf Simeon de Witt, l'advocat John Rutherfurt i el governador Morris, conegut com el Pla dels Comissionats i un pla de reflexió, l'Eixample de Barcelona de 1859 de l'enginyer Ildefons Cerdà. Es tracta de dos projectes molt diferents però són els que millor mostren el gran potencial d'aquesta forma urbana. 


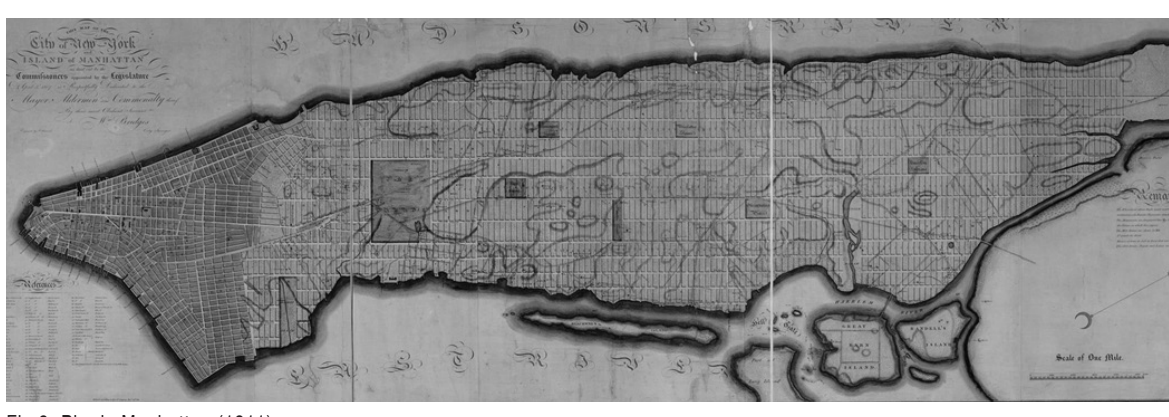

Fig.3: Pla de Manhattan (1811).

Els eixamples de Manhattan i de Barcelona entronquen amb la tradició de l'urbanisme dels segles XVIII i XX. En efecte, el Pla de Manhattan és dels darrers plans d'ordenació de sòl, però l'aportació d'un viari modern i generós li atorga un valor extraordinari, precursor dels nous plans d'alineacions del XIX. El Pla de Barcelona realitzat en plena efervescència dels eixamples també entronca amb el planejament urbanístic que caracteritzarà tot el segle XX, avançant aspectes normatius, econòmics, reparcel-la toris i de gestió.

\subsubsection{El Pla de Manhattan de 1811}

Aquest treball fou encarregat per el City Council el 1807 als Comissionats Simeon de Witt, "surveyor", John Rutherfurd, advocat i el Governador Morris. El treball fou aprovat el 1811 després d'un llarg període de treball d'ajust al territori, realitzat per John Randell Jr., enginyer i “surveyor" en cap de la Comissió.

Dels Comissionats destaca la figura de Simeon de Witt, agrimensor i cartògraf de reputat prestigi. Va ocupar el càrrec de General "surveyor" de l'Estat de Nova York durant cinquanta anys. Es va fer famós per un excel-lent plànol de l'Estat de Nova York, realitzat el 1802 a la escala aproximada de $1: 300.000$.

El Pla de Manhattan consta d'un únic plànol de 2,4 m de llarg realitzat a una

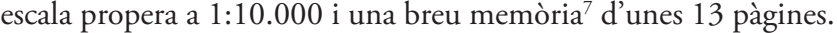

No hi ha mencions específiques sobre altres ciutats de referència per a l'elaboració del Pla. En canvi, sí que hi ha algunes mencions ocasionals a models desenvolupats en altres ciutats.

\section{Antecedents}

Amb anterioritat, el 1792 s'havia presentat el Pla per Washington de Ellicot, de caràcter monumental, que la Comissió va descartar com a referència, ja

7 Memòria del Pla de Manhattan que les diagonals no eren segons els Comissionats una bona solució atesa la pèrdua d'espais que comportava. El Pla de Detroit de 1807 tenia també un nombre important de diagonals i per tant, tampoc devia tenir el beneplàcit de la Comissió.

Altres plans anteriors, com el de W. Penn per Philadelphia ${ }^{8}$ de 1682, de caràcter limitat, presentaven un clara retícula ortogonal, però els carrers normals eren de 50 peus $(15,24 \mathrm{~m})$ quelcom menys que els adoptats a Nova York i l'encreuament central de 100 peus $(30,48 \mathrm{~m})$ igual que les avingudes del Pla de Manhattan. Les mançanes de Philadelphia tenien una superfície compresa entre 129,54 x 152,4 m i 129,54 x 205,74 m, i eren tan grans que es van subdividir introduint carrers a l'interior; al 1762 ja estan totes les mançanes subdividides per un o més carrers i per tant, no servirien com a referència per a Manhattan, però segurament sí les múltiples subdivisions que no estaven gaire lluny de la proposta final de mançana de 200 peus $(60,96 \mathrm{~m})$ d'ample.

\section{Característiques del Pla de Manhattan}

El Pla de Manhattan presenta molts dels atributs dels grans eixamples del XIX:

- Una gran dimensióp . El Pla de Manhattan és un dels projectes d'eixample de major dimensió mai realitzats, amb una extensió de 4.613 ha. En aquells moments el sòl urbà traçat era de 739 ha de les que hauríem de deduir el sòl guanyat al mar, tot i que ocupat per les edificacions hi havia molt menys sòl. El nou projecte multiplicava per 6-7 vegades la ciutat existent. El 1807 Manhattan tenia 85.000 habitants i la nova extensió es proposava per 400.000 més.

- Un bon traçat. La disposició longitudinal del traçat que segueix la directriu longitudinal de l'illa és el que millor s'adapta al territori i al seu perímetre. Les vies més amples, les avingudes, es posen en el sentit longitudinal i els carrers de menor amplada és disposen en el sentit transversal.

- Un viari modern. L'extraordinària amplada de 100 peus $(30,48 \mathrm{~m})$ de les avingudes i la bona dimensió dels carrers ordinaris de 60 peus $(18,29 \mathrm{~m})$ permeten assegurar la vigència de la utilització dels carrers en l'actualitat. Excepcionalment 15 carrers tenen una amplada equivalent al de les avingudes $(30,48 \mathrm{~m})$. L'interval de separació entre aquests carrers més amples oscil.la entre cada 7 a 15 dels ordinaris més estrets.

- La malla. El traçat s’organitza segons una retícula ortogonal de 12 avingudes i 155 carrers. Dues grans intervencions sobre el traçat es produiran el

8 Segons J. Reps, el Pla de Philadelphia tenia força similituds amb la proposta de R. Newcourts per a la reconstruccio de Londres de 1666 després del gran incendi.

9 M. de Solà-Morales en l'article "Los ensanches, una definición" de 1976 planteja la gran dimensió com una caracteristica dels eixamples del XIX. La gran dimensió és necessària per a poder introduir un projecte de gran modernitat com són els eixamples. 


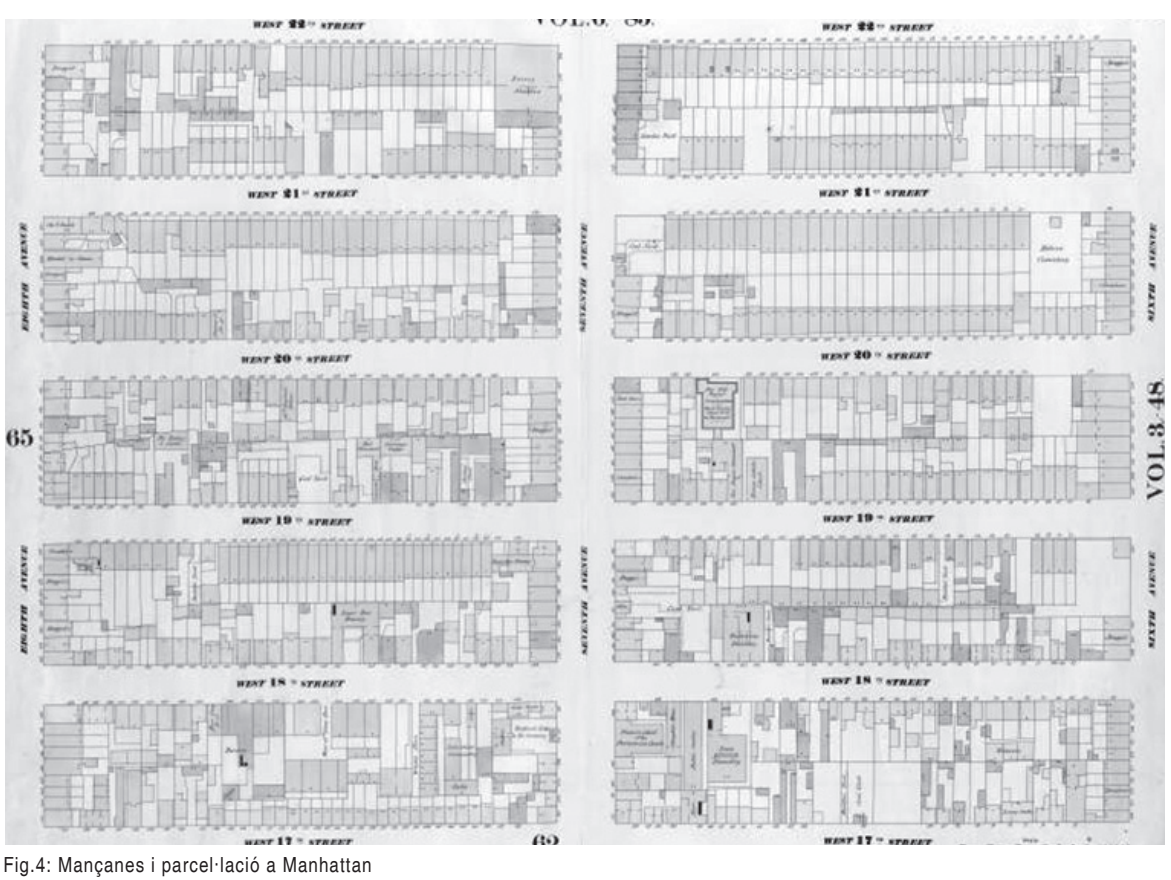

Fig.4: Mançanes i parcell'lació a Manhattan

1832 amb la construcció de la Avinguda Lexington i el 1836 amb la construcció de la Avinguda Madison dins la trama com a noves avingudes que dividiran en dos les llargues mançanes delimitades per les avingudes $3^{\mathrm{a}}$ i $5^{\mathrm{a}}$. Aquesta és una resposta força inicial a la clàssica crítica d'aquest projecte de manca de vialitat en sentit longitudinal.

- Una gran vialitat. El 33\% de la superfície de la malla genèrica està destinat a vialitat, i només el 67\% es destina a la mançana. Aquest terç del sòl destinat a les avingudes i els carrers permetrà que la ciutat tingui grans opcions en l'ordenació de la mobilitat, i una gran intensitat de l'edificació.

- Una sorprenent mançana. L'opció d'una mançana ${ }^{10}$ de gran superfície, 160.000 peus $^{2}\left(14.864 \mathrm{~m}^{2}\right)$ absolutament congruent amb totes les altres opcions projectuals, contrasta amb la proporció adoptada per a la mançana i sobretot en els seus costats de 800 i 200 peus (243,84 i 60,96 m). Aquesta proporció allargada de 4:1 és ideal per a activitats que requereixen façana com l'habitatge, les oficines i els comerços; però la poca amplada de 60,96 m que no donarà lloc a pati de mançana, impedirà la compatibilitat amb altres activitats darrera els habitatges per manca d'espai. La indústria, els equipaments i les dotacions es situaran en façana, ocupant el lloc de l'habitatge.

10 El procés d'ajust fa que les manç̧anes tinguin diferents allargades, hem utilitzat les que considerem més caracteristiques.
- Les activitats a la mançana. La cara curta de la mançana donarà front a les avingudes i la llarga als carrers. Com a conseqüència, en els fronts a les avingudes, molt més concorreguts, és situarà el comerç, mentre que els carrers quedaran exclusivament destinats als habitatges i a algun equipament. Hi ha un gran contrast entre el front de les avingudes i el dels carrers. Probablement i vist des de l'actualitat (sempre és facil opinar temps desprès) una mançana de la mateixa superfície però d'una proporció 2:1, de 172,4 x 86,2 m, hagués equilibrat millor la relació de façanes així com permès l'aparició d'interiors de mançana i els usos compatibles amb aquest espai interior. Una altra opció, menys ponderada, hagués sigut incrementar el nombre d'avingudes sense variar la mida curta de la mançana .

- El parcel-lari. En la pràctica, la proporció 4:1 de la mançana es portarà al parcel.lari on, d'una manera quasi repetitiva, les parcel.les mantindran la mateixa proporció i mesuraran 7,62 m de façana i 30,48 m de fons. La mançana és parcel.la amb dos fronts de 8 parcel-les sobre les avingudes i altres dos fronts sobre els carrers amb 24 parcel.les a cada costat.

- Els espais lliures. La proposta d'espais lliures del Pla de Manhattan neix coixa davant l'opció de la Comissió d'entendre que el litoral ja compleix aquesta funció. La proposta de la Comissió és per tant molt reduïda i es centra en una esplanada d'usos militars i col-lectius de 96 has, un espai de mercat de 23 ha, un parc fluvial a Harlem de 32 ha i 6 places o petits parcs que ocupen en general 4 mançanes d'unes 7,5 ha cadascuna. En total, amb unes 200 ha. cap el $1850 \mathrm{i}$ amb una població de 600.000 hab, la ciutat nomes tenia 40 ha d'espai públic. La proposta d'un Parc Central a la dècada de 1850, amb una proposta inicial de 310 ha, ampliada poc després fins a les 341 ha, capgirarà aquesta mancança d'espais lliures públics i crearà un referent en els tipus de parcs urbans del segle XIX Les ciutats que no puguin optar per un parc central desenvoluparan un conjunt de parcs més petits interrelacionats amb avingudes i bulevards (Parc System).

- Equipaments. El Pla dels Comissionats no fa una proposta específica d'equipaments, més enllà d'un espai de mercat i un d'esplanada militar.

Fig.5: Exemples de carrers (esquerra) i d'avingudes (dreta) de Nova York.
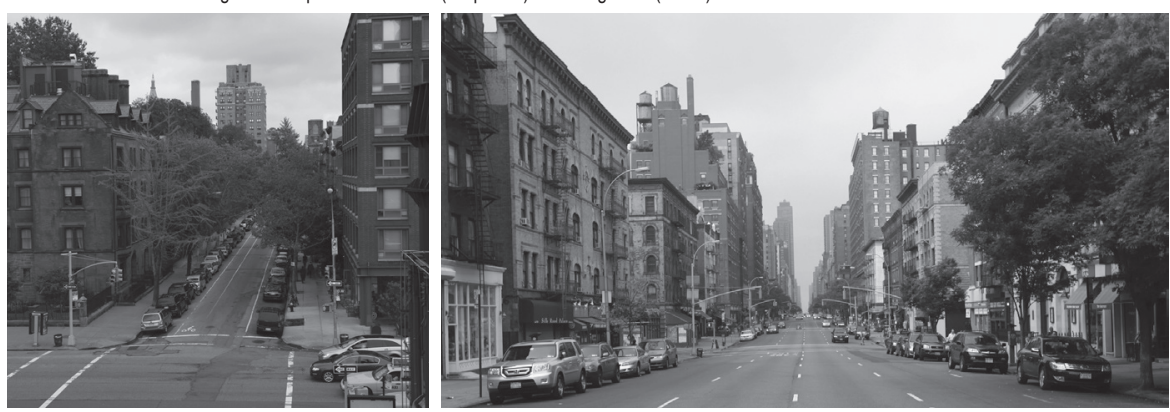
El Pla de Manhattan, malgrat de la mançana tant allargada, és un veritable eixample amb una potent xarxa viària de molt rigorosa execució. La capacitat i la flexibilitat que ha demostrat per acollir activitats molt diverses i l'alta intensitat de l'edificació en que ha estat sotmès en diferents indrets evidencia l'èxit d'una trama pensada inicialment pel creixement residencial, però que amb el pas dels anys ha acollit les activitats més diverses fins a convertir-se en un gran centre de negocis tot compatibilitzant les activitats productives, comercials i residencials. Es aquesta capacitat de mantenir les activitats centrals i les residencials a l'hora el que li confereix un valor excepcional que poques ciutats tenen en les seves trames centrals.

A Manhattan s'ha desenvolupat un tipus arquitectònic singular, el gratacels, que si bé te l'origen a Chicago, podem dir que la seva millor expressió és troba aquí.

El 2010 el districte de Manhattan tenia una població de 1.586.ooo hab. i uns 2.100.000 llocs de treball, en una superfície de 5.943 ha.

\subsubsection{El projecte d'Eixample de Barcelona de 1859}

Si el Pla de Manhattan té un caràcter de pioner (1807-11), hi podríem afegir també intuïtiu, el projecte d'Ildefons Cerdà té un caràcter reflexiu. Cap pla d'aquesta època té una documentació tan amplia. El contingut de les memòries i dels diferents documents són realment un tractat d'urbanisme, probablement el primer tractat modern.

El Pla d'Eixample de Barcelona ve precedit d'un conjunt d'intents d'ampliar la ciutat. Les primeres propostes són de 1838. En general es tracta de petites extensions que es situen fora de la muralla davant de la Rambla on avui és la plaça de Catalunya. Aquestes propostes aniran creixent en mida fins plantejar-se entre la ciutat de Barcelona i la Vil.la de Gràcia. Sistemàticament estaran rebutjades per Govern central.

Aprofitant el "bienni progressista" de 1854-56 amb els lliberals al Govern, s'iniciarà l'enderroc de les muralles el 1854 i els actes preparatoris pel desenvolupament de l'Eixample el 1855.

L'enginyer Ildefons Cerdà serà l'encarregat de realitzar el "Plano topográfico de los alrededores de Barcelona" de $1855^{11}$ que servirà de base pel concurs municipal d'eixamplament de la ciutat. Aquest Plànol realitzat a la escala de 1/5.000 és una fita dins la cartografia espanyola per la seva qualitat i va rebre els elogis de geògrafs importants com Pascual Madoz. És el primer plànol amb corbes de nivell a Catalunya. Aprofitant el moment, Cerdà va sol.licitar al Ministeri de Foment el poder procedir amb els estudis per preparar
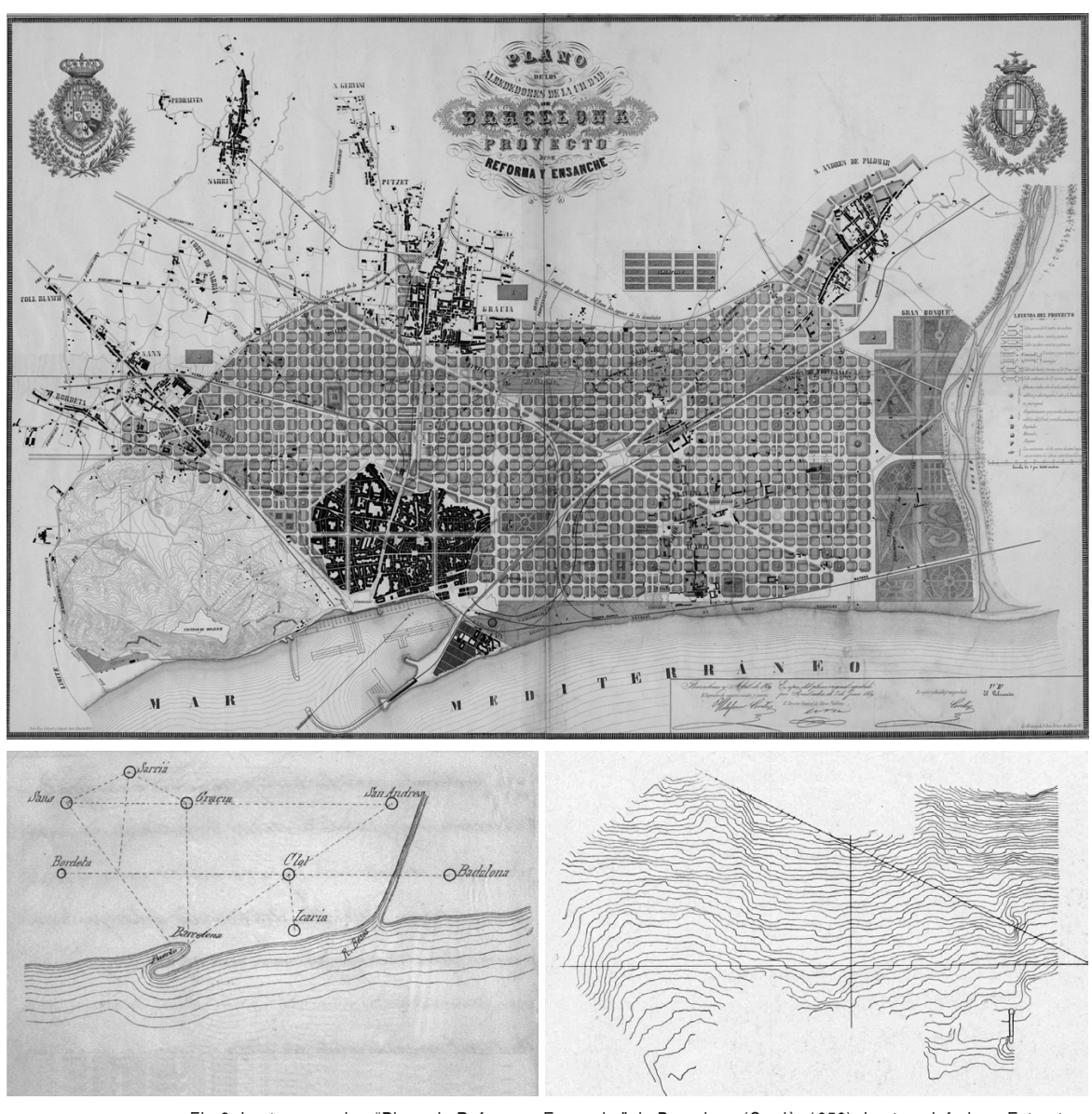

Fig.6: Imatge superior: "Plano de Reforma y Ensanche" de Barcelona (Cerdà, 1959). Imatges inferiors: Estructura territorial de l'Eixample (Cerdà ,1855).i adeqüació topogràtica del traçat.

l'Eixample, qüestió a la que va accedir el ministeri. El 1859 l'Ajuntament de Barcelona va convocar un concurs ${ }^{12}$ del que va resultar guanyadora una interesant proposta de l'arquitecte Antoni Rovira i Trias, especialment pel que fa a la proposta d'espais públics i equipaments. Finalment el Govern ratificarà la proposta de Cerdà davant la proposta municipal de Rovira i Trias. Això farà que durant gairebé 100 anys l'Eixample no sigui ben vist políticament ni massa acceptat socialment per les continues obres que es realitzaven. Arquitectònicament no hauria de ser així ja que els millors edificis modernistes de Barcelona es troben a l'Eixample i els moviments arquitectònics posteriors han realitzat interessants aportacions en aquest àmbit. 


\section{La geografia del Eixample}

El pla de Barcelona delimitat entre els rius Llobregat i Besòs i entre el Mar i la Travessera romana és un territori excel.lent per desenvolupar un eixample. Bona orientació, prop dels camps de conreu i freqüents i suaus rieres que permetien un bon desguàs en cas de pluja.. Els grecs no haguessin dubtat de fundar-hi una ciutat si hi sumem la possibilitat de situar un port al redós de Montjuic. El gran assolellament, un pendent suau entre l'1 i el 5\%, si exceptuem algunes zones del Poblenou, la gran continuïtat amb els teixits del Pla: Barcelona, Gracia, Sant Martí de Provençals, Sant Andreu...i la manca de rius o d'elements topogràfics significatius a l'interior, van fer del Pla de Barcelona un territori excel.lent per desenvolupar-hi un eixample. Unes altres condicions no haguessin permès a Cerdà de realitzar una proposta tan gran en extensió

\section{La higiene}

Cerdà incorporarà al projecte d'Eixample una sèrie d'innovacions higienistes resultat del corrent de l'època i, sobretot, del resultat dels seus exhaustius treballs d'anàlisi i estadística sobre la ciutat i la classe obrera.

Cerdà escollirà la direcció dels vents frescos i secs dominants de sud oest a l'estiu: el garbí. Els carrers prendran aquesta directriu i evidentment la seva perpendicular sud est formen la malla. Com a conseqüència tots els carrers tindran les mateixes hores de sol. Com que no te sentit afavorir cap d'aquestes orientacions acaba fent els costats de les mançanes iguals, la qual cosa dóna lloc a una maçana quadrada, on la diagonal marca el nord.

Proposa un carrer on l'edificació no tindrà més alçada que l'ample del carrer amb el que s’assegura una bona il.luminació i ventilació dels edificis.

Adopta una mançana de grans dimensions de forma que sigui quin sigui el nombre de cares edificades sempre existiran grans jardins o patis de mançana on podran ventilar els edificis.

Des del punt de vista de la higiene els carrers incorporaran en el subsòl les xarxes de clavegueram i de proveïment d'aigua corrent.

Cerdà també incorpora una interessant proposta de parcs i equipaments tant a l'escala local com a la escala de la ciutat. La manca d'instruments legals ${ }^{13}$ no va permetre desenvolupar aquests sistemes. Es tracta d'una proposta massa avançada al seu temps.

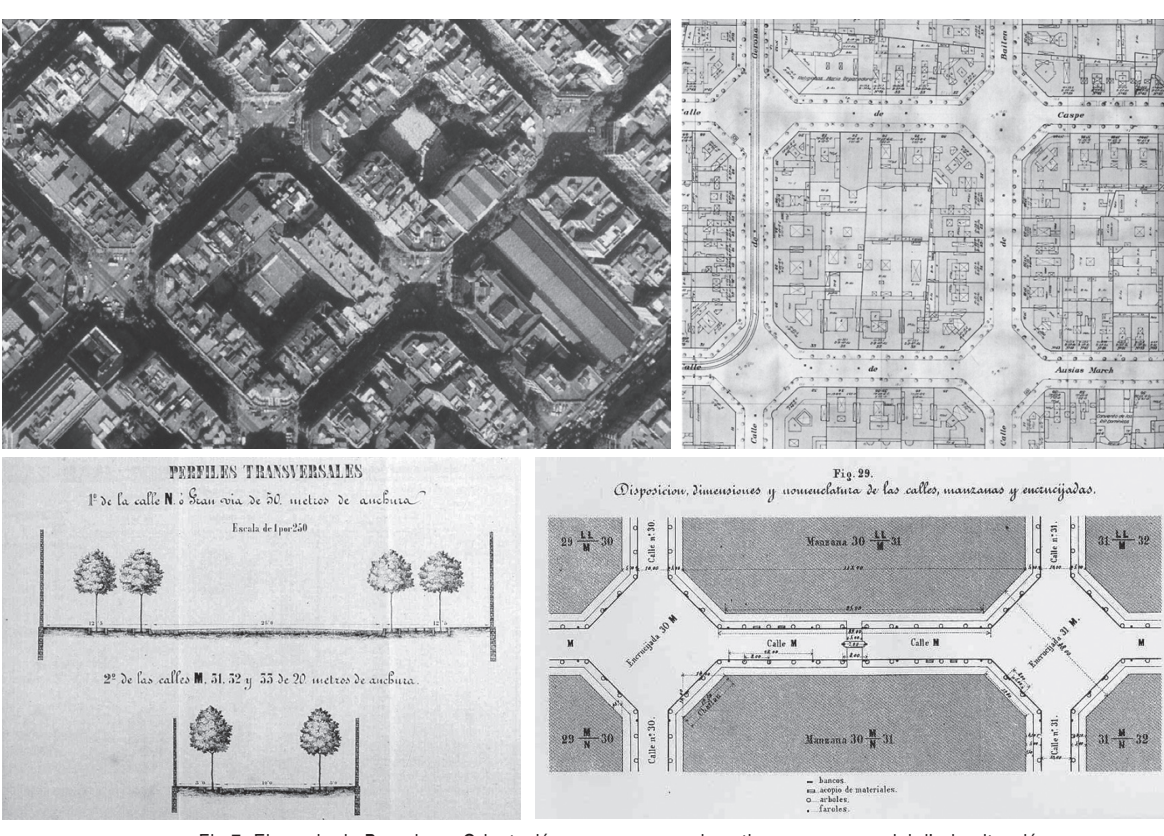

Fig.7: Eixample de Barcelona: Orientació, mançanes, seccions tipus carrers, model d'urbanització.

\section{El traçat}

El projecte d'Eixample conté un doble traçat. Per un costat una estructura territorial amb tres grans vies: Paral.lel, Meridiana i Rambla-Passeig de Gracia que conflueixen al Port i comuniquen amb les valls d'accés al Pla, Llobregat i Besós, i amb els nuclis centrals del Pla. Finalment, projecta una quarta via territorial també de gran dimensió, la Gran Via de les Corts, que cerca la relació més enllà dels rius: Baix Llobregat, Pla de Barcelona i el Maresme. La Diagonal és un element sobreposat de relació interna entre els nuclis del Pla de Barcelona. Es tracta de vies de gran longitud i de gran amplada: 40 , 50 o $60 \mathrm{~m}$.

Pel que fa a la xarxa urbana la proposta consta d'uns carrers molt amples ${ }^{14}, 20$ $\mathrm{m}$, que es situen formant una xarxa ortogonal quadrada de $133 \mathrm{~m}$ entre eixos. Es complementa amb alguns carrers més grans com Urgell, Aragó, Rambla de Catalunya i Rondes, de 30 m d'ample, i el Passeig de Sant Joan de 50 m.

Els carrers tenen una secció molt democràtica. Un $50 \%$ es dedica a vianant i l'altre 50\% es destina als carruatges. Això dóna lloc a dues voreres arbrades de $5 \mathrm{~m}$ i una calçada central de $10 \mathrm{~m}$. La calçada avui té 4 carrils de circulació i/o aparcament.

14 Amb una mitjana d'ample dels carrers de la Barcelona emmurallada de 3,4 $\mathrm{m}$ la proposta de Cerdà de $20 \mathrm{~m}$ és absolutament renovadora per no dir revolucionaria. 


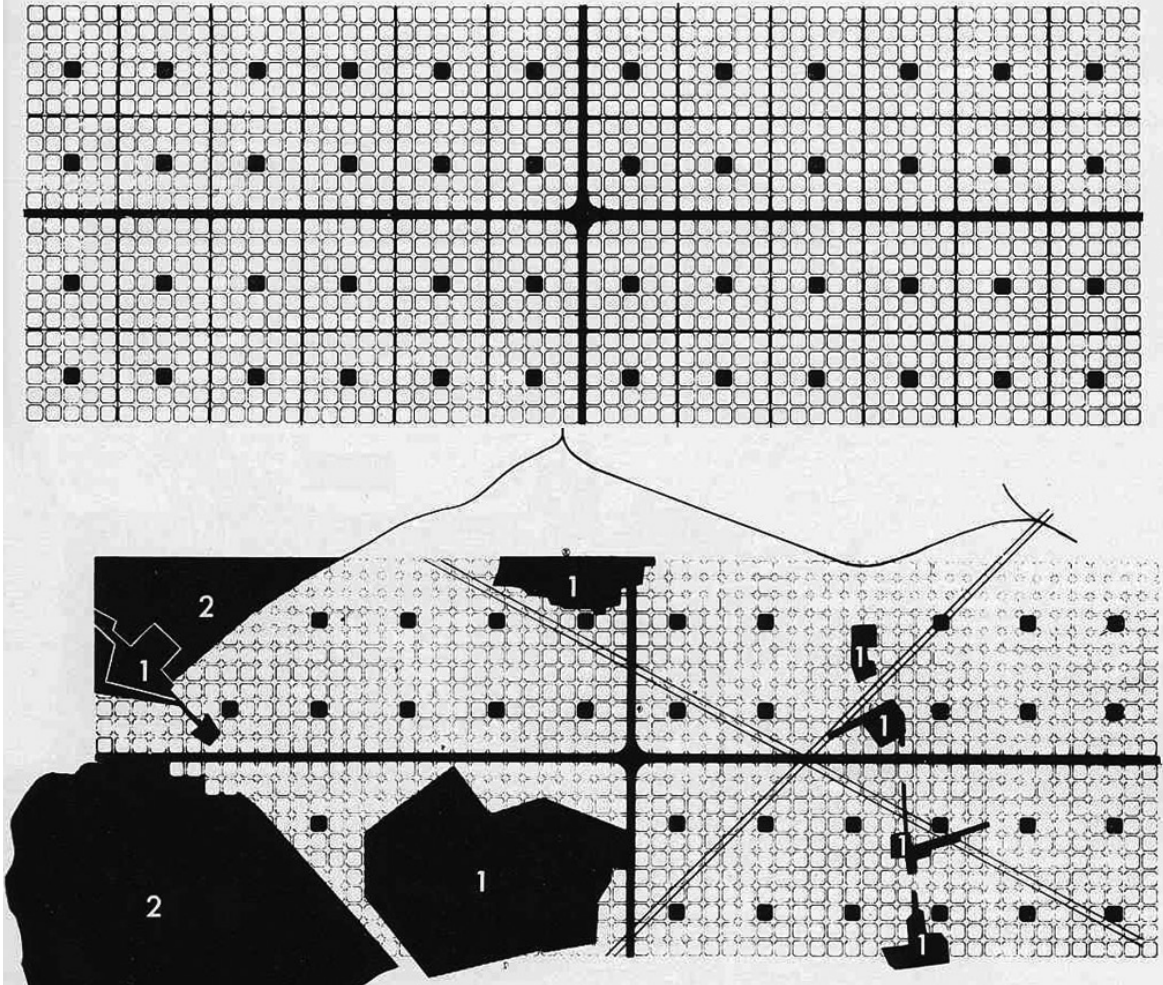

Fig.8: Distribució d'equipaments locals i vialitat principal (M.Domingo)

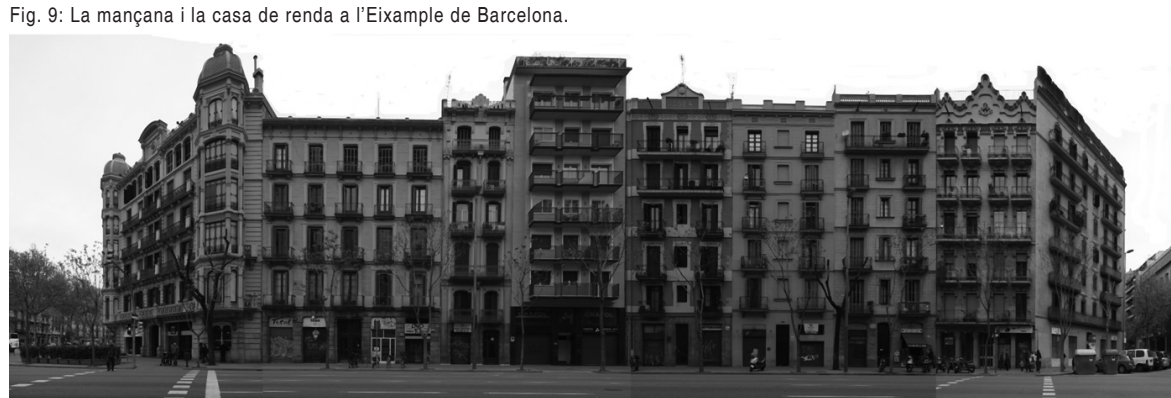

\section{La tecnologia}

La reflexió sobre l'aplicació del ferrocarril a la ciutat com a sistema de transport $\mathrm{i}$ atenent als possibles girs dels vehicles farà que Cerdà incorpori uns xamfrans de gairebé $20 \mathrm{~m}$ en totes les interseccions viàries. La cruilla amb els xamfrans es convertirà en un del punts més singulars de la nova trama urbana i facilitarà la implantació de tota mena de vehicles de transport al llarg dels anys: tramvia, trolebus, bus, vehicles privats, etc.

\section{La mida de l'Eixample}

La gran dimensió ${ }^{15}$ de l'Eixample, unes 2.000 ha, és a dir unes 1o vegades la ciutat antiga, era necessària per poder donar sentit tant al conjunt de la proposta com a la gran modernitat demostrada en totes les decisions adoptades. Tot això la superfície no arriba ni a la meitat de la proposta per Manhattan de 1811.

\section{El sòl}

El sòl s'ordenarà en grans mançanes de $113 \times 113 \mathrm{~m}$ amb les cantonades aixamfranades de 19,8 m. Cadascuna es dividirà en 22-24 parcel.les, una a cada xamfrà, i quatre o cinc sobre els carrers. A conseqüència d'aquestes grans dimensions la mançana tindrà una edificació perimetral, d'entre 20 i 30 m de fondaria, destinada a la construcció de cases de renda i un gran pati interior de més de 50 metres, destinat a jardins o industries majoritàriament. El fet de tenir un pati central és una de les característiques més singulars de l'Eixample i que més el diferencia d'altres eixamples.

\section{L'ús}

La mançana regular presenta una planta baixa d'usos no residencials i una corona exterior perimetral al carrer en plantes pis d'ús majoritàriament residencial. Això dona una barreja d'usos dins una mateixa mançana molt important.

Si l'ús de la mançana es preveu exclusivament per habitatges s'introduiran passatges aconseguint d'aquesta manera molta més longitud de façana. Si pel contrari el que és cerca són usos no residencials com indústries o equipaments que requereixen molt sòl, les mançanes s'agruparan en super-mançanes de 2, 4 i fins i tot 9 mançanes regulars amb els corresponents carrers.

\section{La casa de renda}

La casa burgesa o "casa de renda" que es desenvoluparà a l'Eixample, a part de les del xamfrà, serà un edifici de 9-12 m d'amplada majoritàriament $\mathrm{i}$ 15 Vegeu nota 9. 
una fondària entre 26 i $30 \mathrm{~m}$, de planta baixa i 4, 5 o 6 plantes d'alçada. La planta baixa es destinarà a usos no residencials: comerços, tallers i garatges. La planta superior immediata s'anomena pis principal degut a que en molts casos hi ha un sol habitatge on viu el propietari. Les plantes superiors són de dos habitatges per replà i es destinen al lloguer. En no tenir inicialment ascensor els edificis presentaven una veritable estratificació social de forma que les classes benestants ocupaven la planta principal, la classe mitjana els pisos entremitjos i la classe obrera les plantes més altes. La façana de l'edifici també mostrava aquesta estratificació social amb la presència de tribunes i altres elements singulars a la façana del pis principal, mentre que les alçades dels pisos, les amplades i fondàries dels balcons s'anaven reduint a mesura que s'apropaven a la coberta.

Els habitatges eren de gran dimensió i ventilaven al carrer i al pati de mançana . La façana al carrer era dominada pel mur amb balcons i altres obertures verticals, mentre que la del pati incorporava una galeria molt vidriada que accentuava l'ús més domèstic d'aquesta part de la casa. El terç central de l'edifici acollia les escales d'accés, les habitacions més petites i les activitats de servei. Lateralment, junt a la mitgera es disposaven patis mancomunats de forma que actuaven com façana mentre no es construïa la casa veïna. Aquest tipus de dos habitatges per replà es manté durant tot el segle XIX fins 1940, quan es generalitza el tipus de 4 habitatges per replà. A inicis del segle XX ja trobem alguns casos de 4 habitatges per replà en les dues darreres plantes de l'edifici i en els anys 1920 algun cas on la totalitat de l'edifici és de 4 habitatges per replà. Amb aquest model es trenca l'excel-lent doble orientació-ventilació, a carrer i a pati de mançana, dels habitatges de l'Eixample.

\section{Altres elements innovadors}

La proposta de Cerdà va més enllà del traçat viari. El projecte inclou un conjunt d'espais lliures i grans equipaments a escala de la ciutat: escorxador, hospital, hipòdrom, gran parc del Besós..., i un conjunt d'equipaments a nivell de barri distribuïts cada 20 o 25 mançanes $^{16}$. Malauradament la manca d'instruments legals no va permetre el desenvolupament d'aquestes dotacions ja que la legislació només regulava l'expropiació pel viari i per la construcció de ferrocarrils.

\subsubsection{Altres plans d'eixample}

L'impacte de l'excel-lent projecte de Cerdà tindrà àmplies repercussions ${ }^{17}$ Abans de l'inici de la seva execució altres ciutats ja elaboraran projectes d'eixample. El fort impuls del eixamples al nostre país, amb les corresponents lleis d'eixample, farà que el "zoning" tardi molt a implantar-se al nostre país.
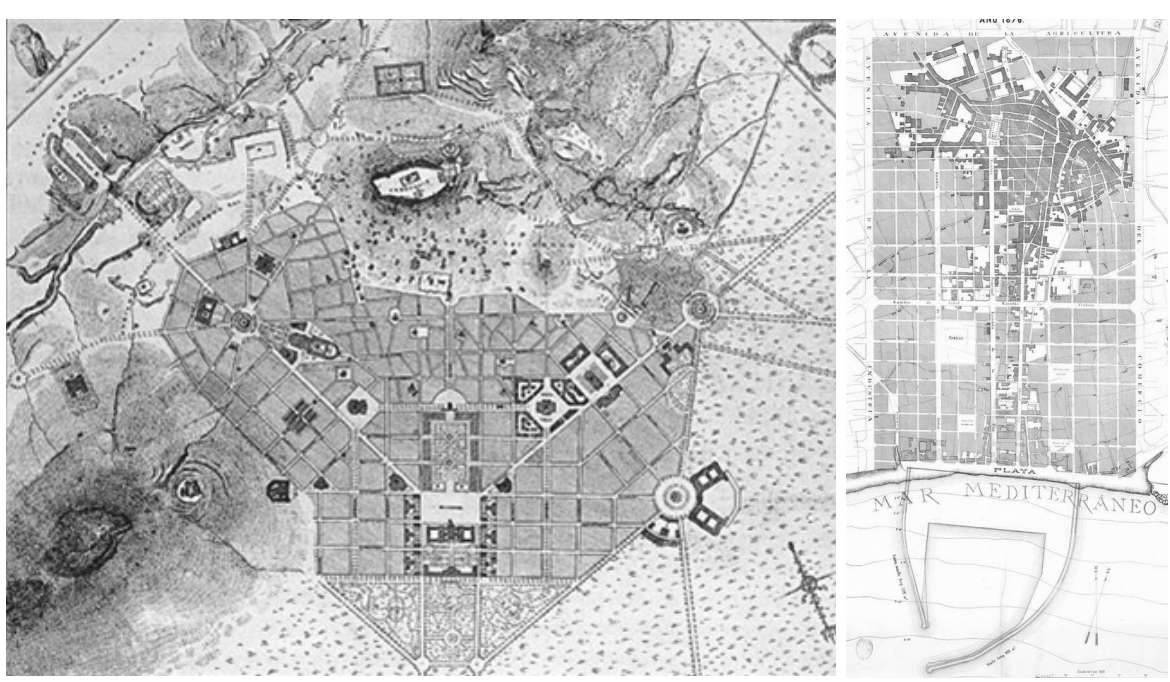

Fig. 10: Esquerra: Eixample d'Atenas. Dreta: Eixample de Vilanova i la Geltrú.

La legislació econòmica de l'eixample no es derogarà fins la primera Llei del sòl estatal de 1956.

Les capitals de província i les grans ciutats de l'estat seran de les primeres ciutats on es redactaran plans d'eixample seguint aquesta forma de creixement: Madrid (Castro, 1860), València (emmurallat, de Monleón i Calvo, 1858; Moleón, Sancho i Calvo, 1861; definitiu, Calvo, Arnau i Ferreres, 1884), San Sebastià (Cortázar, 1864), Gijón (Palacio, 1867), Bilbao (Alzola, Achúcarro i Hoffmeyer, 1876), Pamplona (Esparza, 1888), Cartagena (Garcia Faria 1897), Palma (Calvet, 1901), Lleò (Diez i altres, 1904), entre altres.

A Catalunya la influència arribarà a importants ciutats i viles que redactaran uns eixamples més adaptats a les circumstàncies locals i que és coneixen com "Eixamples menors"18: Sabadell (Molina, 1868; Pascual, 1886), Rubí (Sagalés, 1875), Vilanova i la Geltrú (Gumà, 1876), Mataró (Cabañes i Palau, 1878), Terrassa (Coret, 1878; Pascual, 1910), Badalona (Pons, 1895)

A Europa els eixamples tindran una menor importància. Són destacables a més dels els projectes pioners de Helsinki (1817 i 1875), i d'Atenes (1833), els de Italià: Bari (Trotti, 1866-68); el Vomero (1885) i el Vasto (1889) de Nàpols sorgits del Pla de sanejament de la ciutat baixa de $1885-1888^{19}$ i els barris de Esquilino (1870), Pratti (1870) i Testaccio a Roma (1873), tots ells

\section{J. Esteban: Los ensanches menores, LUB, ETSAB 1976}

19 El "Risanamento" de Napols de 1885 , resultat del fort collera que s'havia produit a la part baixa de la ciutat implicava una forta demolició d'edificisi i la construcció de 18 àrees residencials: Arenaccia, Sant'Eframo Vecchio, Ottocalli, Pont Rossi, Miradois, Materdei, Vomero-Arenella, Belvedere, l'ampliació del barri Amedeo, i dos barris suburbans, molts desenvolupats seguint el model d'eixample. Fruit de la remodelació és desplaçaven 60.000 habitants. 


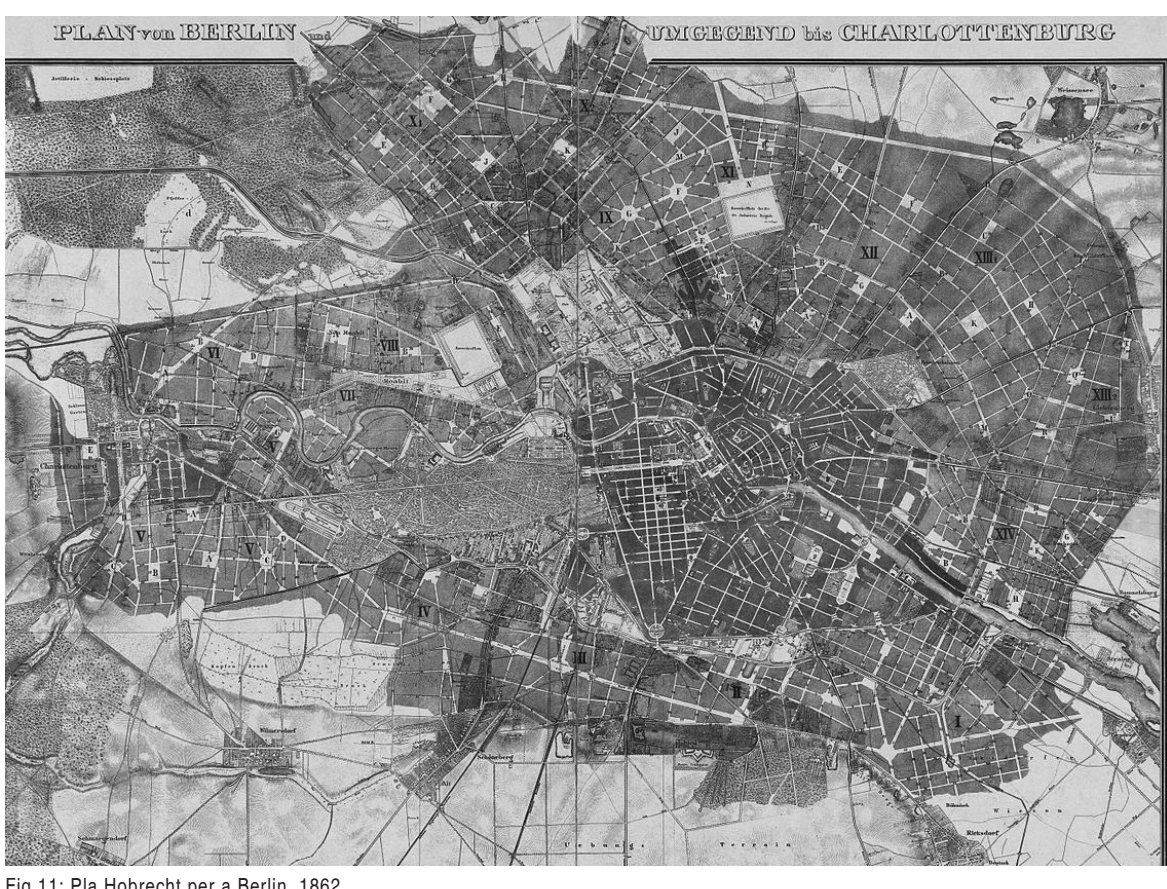

Fig. 11: Pla Hobrecht per a Berlin, 1862.

recollits al Pla regulador de Roma (Viviani,1873). Menys significatius però força antics son el de Florència (Poggi, 1865), Estocolm (1866), la Neuestad de Mainz a Alemanya (Eduard Kreyssig, 1869) i Budapest (1872).

\subsubsection{Una oportunitat perduda: El pla de Berlin de Hobrecht de 1862}

El projecte de James Hobrecht per Berlin de 1856-1862 es proposa amb una gran extensió i amb una gran estructura on sembla que cal definir el gra menut $^{20}$. Els vials projectats tenien entre 25 i 39 m d'amplada, mentre que les mançanes feien $200 \mathrm{~m}$ per $300 \mathrm{~m}$ i en alguns casos arribaven a mesurar $400 \mathrm{~m}$. Es tracta d'unes mançanes absolutament sobredimensionades que fan que el projecte perdi tot valor com referència. Es plantejaran greus problemes de desenvolupament que obligaran a una gran fragmentació de la trama original. La major part de les mançanes foren subdividides en dues, tres, quatre o més mançanes força més petites. La partició de les mançanes, sense una lògica unitària i repetitiva, va fer que el projecte perdés consistència, donant un resultat erràtic i força decebedor. Les places també estaven sobredimensionades. El Pla de Hobrecht és va aplicar fins 1919.

20 Tot i que el projecte de Hobrecht es podia anticipar al concepte de sistemes generals definits pel Pla i sistemes locals definits en el desenvolupament, la manca de reiteració d'una geometria regular ' 'hi fan perdre tota la força que hagués pogut tenir.

\subsubsection{Els eixamples avui}

Els eixamples del XIX, i molt especialment els de Manhattan i Barcelona, són els teixits urbans que tenen unes característiques que més s'aproximarien al que es considerarien paradigmes de l'urbanisme actual:

- Alta densitat

- Misticitat d'usos

- Flexibilitat

- Compacitat urbana

- Capacitat de tenir un transport col-lectiu

També podríem afegir:

- Gran centralitat

- Identitat ciutat-eixample eixample-ciutat

\subsection{Els plans d'avingudes}

Les ciutats emmurallades recentment $\mathrm{o}$ amb topografies externes pronunciades optaran pels models basats principalment en les avingudes tant en la reforma com en el creixement. Tot i que la tècnica és diferent pel que fa a la gestió, la resta d'aspectes és força semblant un cop feta l'expropiació en el cas de la reforma. Generalment en el cas de vies d'entrada a la ciutat s'optarà per amplies vies amb secció d'avinguda i en les vies internes s'optarà en molts casos per la secció de bulevard.

Són significatives les intervencions de reforma i extensió de Paris, els plans de les avingudes de Lisboa, o el creixement sobre avingudes de Montevideo o Saragossa.

\subsubsection{Paris: Hausmann i el segon imperi 1853-1870}

Paris no podrà optar pels eixamples. En primer lloc ha de resoldre un greu problema: la pèssima qualitat de vida del centre. Amb edificacions molt antigues i amb els serveis mínims, el centre de Paris tenia una densitat força alta, amb una mitjana a prop dels $200 \mathrm{hab} / \mathrm{ha}$. Feia poc que les muralles noves (Thiers 1840-44) s'havien construït més que doblant la superfície de sol (127\% d'increment). Hi havia sòl més que suficient pel creixement futur de Paris però insuficient per produir un eixample donades les formes dels perímetres intern i extern del sòl vacant parcialment. Cal afegir que part d'aquest sòl tenia força desenvolupaments fora muralles que poc ajudaven a materialitzar un eixample. El 1859 es van annexionar completament els mu- 


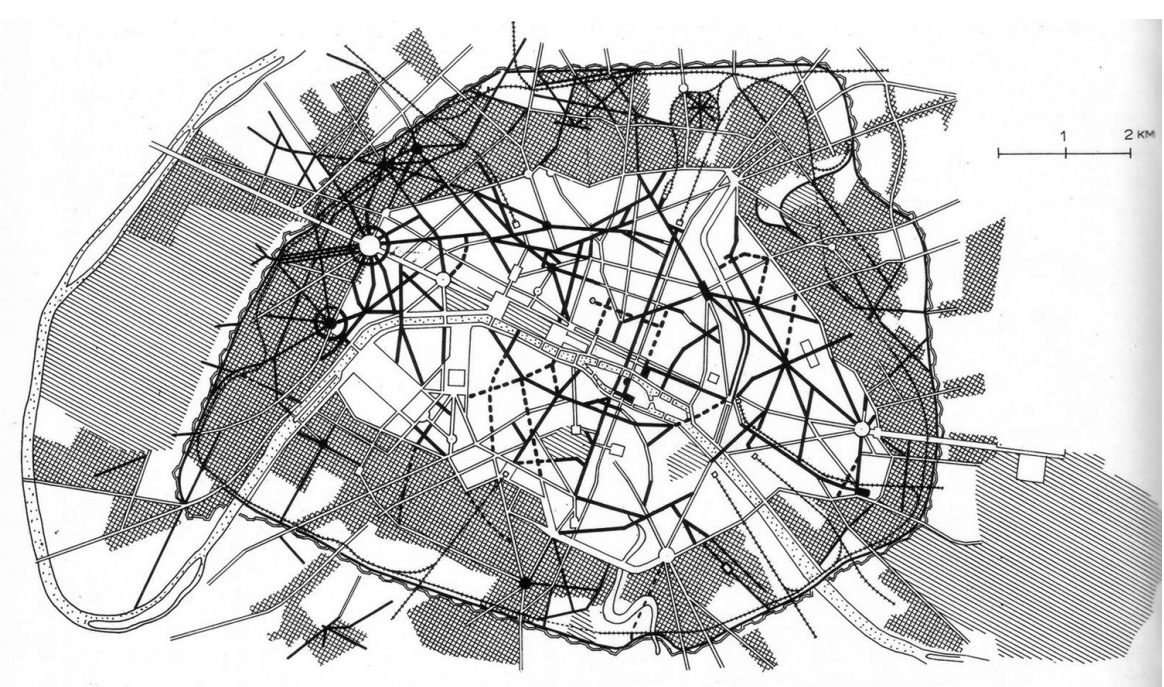

Fig. 12: Intervencions de renovació i d'extensió de Haussmann a Paris (en blanc i tramat respectivament).

nicipis de Belleville, Grenelle, Vaugirard i la Vilette, altres set municipis en gran part i dotze barris mes. Amb vint-i- tres assentaments dins la nova muralla era difícil fer un eixample amb aquestes condicions. El plànol "General de la zone de Paris” de Lefévre de 1859-60 dibuixa l'estat dels terrenys entre la muralla des Fermieux Généraux i la de Thiers amb gran detall i permet apreciar l'altíssim nivell d'ocupació. La muralla des Fermieux Généraux de 1785 no era veritablement militar, tenia valor de control econòmic i això va fer que és construís molt facilment a les afores.

\section{La tradició francesa}

Paris ja havia experimentat diversos processos de modernització de la ciutat sempre amb les muralles presents. Els primers eixamplaments de carrers es produeixen a partir de l'edicte de 1607 i posteriorment amb la ordenança de 1667. Amb l'enderroc de les muralles de la "rive droite" es dóna pas a uns amplis bulevards. La rue de la Ferronnerie és un bon exemple (1669). Aquest carrer es va desenvolupar amb una "servitud d'arquitectura" com la place Royale i la majoria de les noves ordenacions urbanístiques de carrers i places $^{21}$. El carrer es va regularitzar amb un ample de $11 \mathrm{~m}$ i posteriorment es va eixamplar en part a $18 \mathrm{~m}$. Una altra obertura important, de caràcter monumental va ésser la de la rue Soufflot per connectar el "Panthéon" amb els Jardins de Luxemburg. Es va obrir amb dos trams: el primer fins la Rue de Saint-Jacques cap el 1760 (de $20 \mathrm{~m}$ d'amplada) i el segon fins el bulevard Saint-Michel entre 1846 i 1876 (30 m d'amplada).

21 Vegiu J. Sabaté "El proyecto de la calle sin nombre" Arquithesis nำ. Barcelona, 1999.
Però el primer carrer obert amb motius higienistes superposant-se a la trama urbana existent fou la rue Rambuteau. Es va obrir sota la prefectura de C-Ph. Barthelot de Rambuteau ${ }^{22}$ a partir d'un projecte de Cendrié de 1837. Inicialment previst per $20 \mathrm{~m}$ d'ample, va obtenir el permís del consell municipal per un ample de $13 \mathrm{~m}$. Es tracta d'una traça de diverses directrius de 975 m de longitud que uneix el carrer Paradis-au-Marais i la plaça de la Pointe-Sant-Eustache. El projecte es va declarar d'utilitat pública el 1838. Les expropiacions es van realitzar entre 1839 i 1845 , emparades en la llei d'expropiació forçosa de 1833. La intervenció, sobre un barri molt degradat, va generar una gran admiració ciutadana i va ensenyar un camí pel futur de Paris molt més àgil que les lentes ampliacions prèvies de carrers ${ }^{23}$.

\section{La intervenció de Haussmann}

Georges-Eugène Haussmann va ésser nomenat prefecte del departament del Sena el 1853 i va deixar el càrrec a 1870. Va rebre l'encàrrec de Napoleò III de modernitzar París. Fins a les hores el casc urbà de París el formaven un conjunt de carrers medievals, estrets i pestilents que disposaven d'un antic ${ }^{24} \mathrm{i}$ ineficient clavegueram. La modernització es va produir sobre diversos camps: vials, serveis, parcs i edificis públics.

La intervenció més espectacular es va dur a terme obrint avingudes i bulevards dins el teixit medieval. Es van obrir nous vials, rectes, ben anivellats i de gran amplada. Els vials anaven acompanyats d'uns serveis moderns d'abastament d'aigua, gas i clavegueram. En els encreuaments dels vials es posposaven nous equipaments per a la ciutat. La intervenció haussmanniana es completava amb un important conjunt de parcs i equipaments de districte i dos grans parcs a l'est i l'oest de París. Tot aquest treball no s'hagués pogut dur a terme sense la participació de grans tècnics: J-Ch-A. Alphand, enginyer de ponts i camins, responsable de l'obra civil; E. Belgrand, també enginyer de ponts i camins, responsable dels serveis tècnics; J-P. Barillet-Deschamps, jardiner, responsable de les plantacions, la jardineria i el paisatge; i de V. Baltard, arquitecte, responsable de "les Halles" entre d'altres importants edificis públics.

La proposta consistia en realitzar un traçat viari superposat a l'antic teixit urbà per tal de modernitzar-lo i sanejar-lo. Es tracta de vials amplis, al voltant de 25-30 $\mathrm{m}$, rectilinis i amb una parcelllació regular i una ordenació de les façanes regulada per unes estrictes normes d'edificació que asseguraven una imatge final molt unitària malgrat el caràcter fragmentari de la intervenció. Les actuacions també incorporaven vials secundaris de menor amplada. L'expropiació abastava el sò dels nous vials i, tot i que la legislació no ho permetia, els solars amb front a les

22 Rambuteau fou prefecte del departament del Sena de 1833 a 1848. Va finalitzar la urbanització dels Camps Elisis el monument de l'Arc del Triomf dedicat a Napoleó.

23 Vegeu J. des Cars i P.Pinon "Paris.Haussmann" Picard Paris, 1991.

24 La segona pandèmia de còlera de 1832 és va cobrar a Paris 20.000 morts sobre una població de 650.000 habitants. 
noves vies. Es produïa un gran buidat en el teixit urbà. A continuació es procedia a urbanitzar el nou vial: calçades i voreres amb arbrat, l'enllumenat i el mobiliari urbà i en el subsòl tots els serveis urbans $\mathrm{s}^{25}$;. Finalment es venien els solars amb l'intent de recuperar la inversió. El temps de realització era relativament ràpid i els resultats espectaculars. Avui dia encara ens ho semblen. La intervenció també permetia un major control policial de la població ja que era molt més facil accedir als diferents focus revolucionaris davant la dificultat de fer grans barricades. Algunes valoracions apunten que durant el període de Haussmann es van enderrocar aproximadament el 60\% dels vells edificis de París.

La tècnica era tan depurada que pel desenvolupament dels sòls sense urbanitzar, delimitats per la darrera muralla de Thiers, es va continuar amb el mateix sistema formal i estructural, però sense la necessitat d'expropiar, ja que eren els mateixos propietaris qui urbanitzaven i cedien els vials.

\section{Paris i la nova muralla de Thiers}

Paris tenia a les hores 3.437 ha i $384 \mathrm{~km}$ de carrers al centre. Amb la intervenció de Haussmann es van obrir un total de $95 \mathrm{~km}$ de carrers i se'n van suprimir $49 \mathrm{~km}$. Els terrenys periferics incorporats dins la darrera muralla tenien 4.365 ha amb $355 \mathrm{~km}$ de carrers; se'n van obrir $70 \mathrm{~km}$ i se'n van suprimir $5 \mathrm{~km}$. Si atenem a la longitud dels nous carrers la reforma interior només supera en un $36 \%$ a la intervenció exterior.

\section{Les grans obertures}

Les intervencions principals en aquest període van esser l'apertura de $48 \mathrm{ca}$ rrers, trams de carrer o places, entre els que destaquen ${ }^{26}$ :

- Av. de l'Opera (1853-77), plaça (1860-62), el darrer tram (1876-77)

- Blv. Malesherbes (1854-61) i (1858-62)

- Place Etoile (1854-68)

- Rue Rivoli, tram (1854-55)

- Blv. Sebastopol (1854-58)

Blv. Saint-Germain (1855-61) i (1866-77)

- Blv. Saint-Michel (1857-60) i (1859-62)

- Blv. Magenta, final (1859-66)

- Blv. Haussmann (1859-63), (1862-63), (1862-64), (1865-67) i (1868-70)

- Rue Lafayette (1859-67) i (1862-67)

Blv. Raspail (1866-1907)

25 El metro s'incorporarà a partir de 1900.

26 Vegeu J. des Cars P. Pinon opus cited
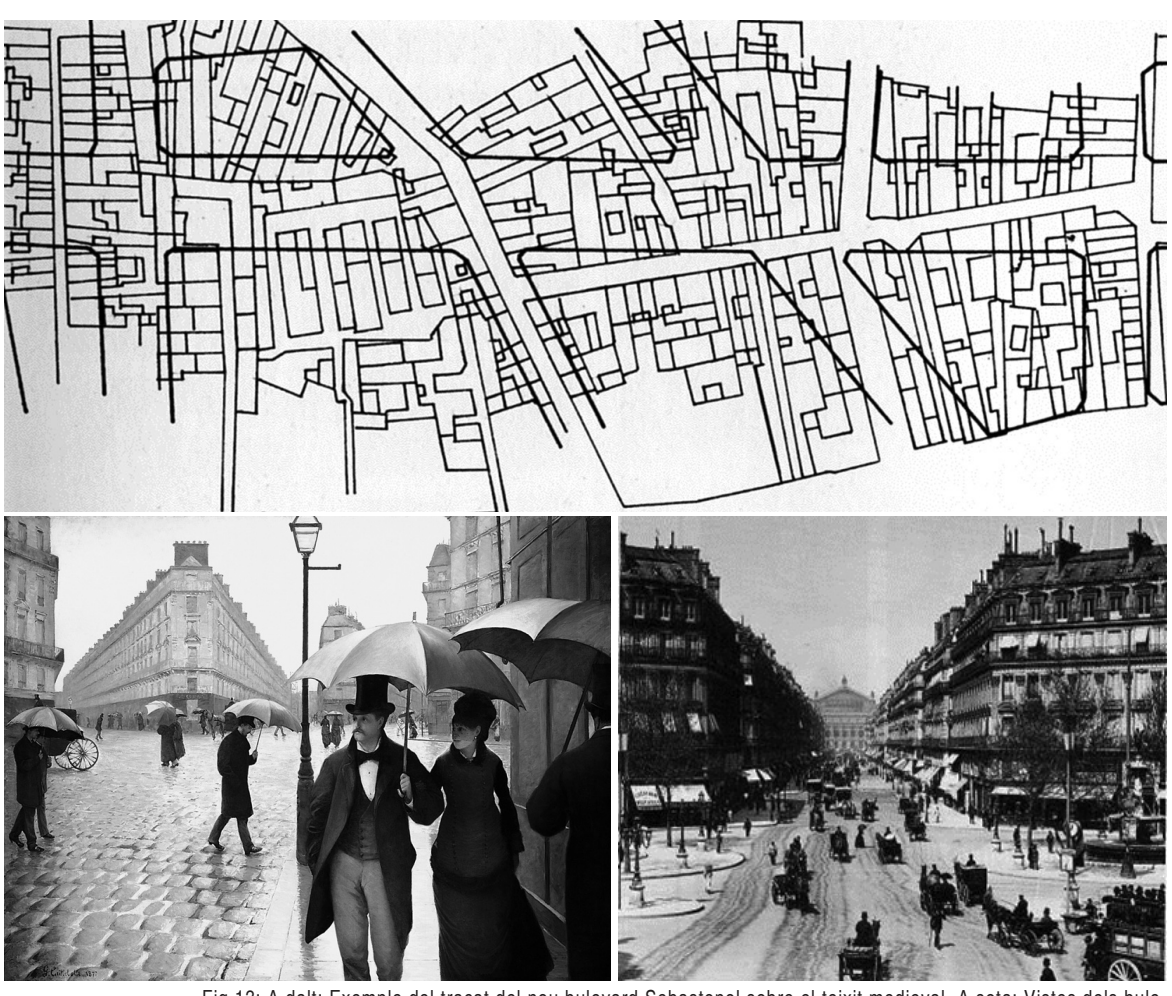

Fig. 13: A dalt: Exemple del tracat del nou bulevards

Serveis, parcs i equipaments

Les obres de clavegueram, $120 \mathrm{~km}$ quan arriba Haussmann, van sobrepassar els $500 \mathrm{~km}$, amb una secció mullada de 3,5 $\mathrm{m}^{2}$ per cada 100 ha. Les obres d'abastament d'aigua van suposar la construcció de $173 \mathrm{~km}$ d'aqüeductes, canals i sifons i un dipòsit de $95.000 \mathrm{~m} 3$ d'aigua.

Es van urbanitzar els grans parcs de París: Bois de Boulogne i Bois de Vincennes. Es van crear cinc parcs de districte: Monceaux, Des Buttes-Chaumond, Montsouris, Champs Elysées i els jardins de Ranelagh. També es van crear 18 jardins públics locals (Places o Squares). En total Alphand va crear o reorganitzar 1934 ha d'espais lliures. A més, sobre els carrers ${ }^{27}$, va plantar 82.000 arbres amb el que va transformar el paisatge de París.

Pel que fa als edificis públics i equipaments es van construir ajuntaments de districte, 13 esglésies, 6 teatres i 7 equipaments entre Hospitals, casernes i presons.

27 Si els carrers tenien més de $26 \mathrm{~m}$ s'hi plantava un rengle d'arbres; a partir de $36 \mathrm{~m}$ dos rengles; a partir dels $40 \mathrm{~m}$ s'afegia un nou rengle central. 

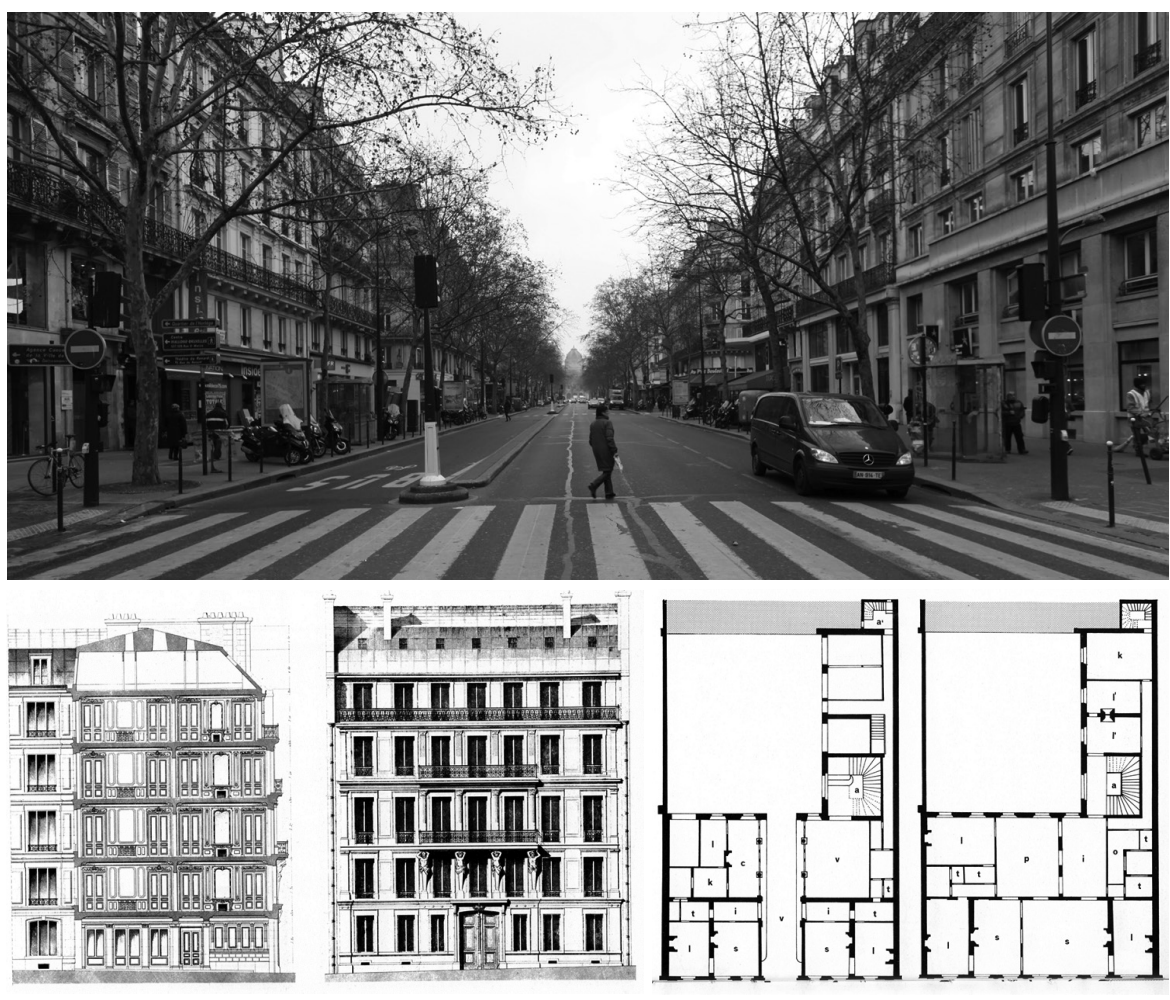

Fig.14: Boulevard Sebastopol-Strasburg i cases burgueses senyorials als Camps Elisis.

\section{El sistema financer de Haussmann}

Inicialment el sistema havia de ser autosuficient. La venda dels solars urbanitzats havia de compensar totes les despeses anteriors. D'entrada l'Estat expropiava els terrenys i els edificis, després enderrocava els vells edificis, urbanitzava els nous carrers i finalment es venien els solars que s'havien de construir segons un precís plec de condicions. Per evitar el desfasament comptable degut al temps transcorregut entre l'expropiació i la venda de solars, Haussmann va sol-licitar préstecs per un valor que oscil-lava entre 50 i 80 milions de francs anuals. Posteriorment, a partir de 1858, serà la "Casse des traveaux de Paris" l'instrument privilegiat de finançament que facilitarà molt el procés al centralitzar tots els aspectes financers. Això permetia destinar anualment a l'apertura de carrers el doble del pressupost municipal de París. Però no era només un desfasament comptable i les intervencions generaven continues pèrdues. El 1870 la pèrdua acumulada era ja de 1.500 milions de francs. Per això, Haussmann va ésser cessat en el càrrec.

\section{El Paris de Haussmann}

La ciutat resultant de la intervenció de Haussmann és una ciutat estructurada a partir d'un viari molt ample que pren una forma diagonal i conflueix sovint en unes places. Es configura una creu central (Sebastopol-Rivoli); una xarxa força radial que reforça la connexió del casc central amb els nous terrenys perifèrics (Malesherbes, Voltaire...) i un conjunt d'intervencions més allunyades que tendeixen a completar anells viaris (St. Germain oest, Marechaus-Pyrenées...). Tot i que Haussmann ja parla d'aquestes tres xarxes, segons les seves pròpies memòries, per ell només tenen valor comptable.

\section{Els elements del teixit urbà}

Les àmplies vies de 25-30 m tenen dues seccions generals: avinguda o bulevard. En el cas de les avingudes consten de dues àmplies voreres a cada costat de la calçada central de circulació amb enllumenat i arbrat. En el cas del Bulevard Sebastopol, que en realitat té secció de carrer, dels $30 \mathrm{~m}$ d'ample és destinen 8 a cada vorera i 14 a la calçada central de circulació. En el cas dels bulevards pròpiament dits la secció consta d'un passeig central ampli d'uns $14 \mathrm{~m}$.

Les mançanes resultants són força diferents, sovint amb la presència de formes triangulars i de dimensions reduïdes. No conformen pati de mançana. Es compensa amb uns bons patis a cada edifici.

El parcel-lari pensat per edificacions entre mitgeres és força regular, ortogonal als vials i d'una amplada molt variada. Per edificis de cinc forats a la façana la parcel.la té uns $16 \mathrm{~m}$ d'ample. Hi ha força parcel.les entre 14 i $20 \mathrm{~m}$ en funció del barri. Els nous edificis tenen planta baixa i 3, 4, 5 ó 6 plantes pis a més del sota coberta.

Els nous habitatges burgesos donen façana al carrer i a un pati de parcel.la força ampli de 60 a $80 \mathrm{~m}^{2}$. Des del carrer s'accedeix al pati a través d'un pas exclusiu i des del pati a les diferents escales de veïns. Això permet una gran continuïtat del comerç a la façana del carrer i complementar l'ús de la planta baixa al pati interior. En moltes ocasions el pati interior s'enfronta al de la parcel.la veïna generant un major espai de ventilació i moltes vegades es mancomuna el pati i se’n obté un de més gran en la planta baixa. Els habitatges principals es situen sobre el carrer i els secundaris sobre el pati interior. Tenen 4 ó 5 estàncies grans a més de les del servei en el cas d'habitatges principals. Els habitatges es destinen al lloguer.

\section{Haussmann un referent}

L'èxit de la innovació hausmanniana serà ràpidament reconegut. Les noves avingudes seran un referent urbà, econòmic i social. Els artistes reflectiran 
millor que ningú les noves transformacions. París es convertirà en el mirall del món.

Aquest tipus de ciutat serà el referent en la reforma urbana de la segona meitat del segle XIX i força avançat del XX. El carrer Alfonso I de Zaragoza (1866-1900), la Gran Via de Granada (1895-1903), la Via Laietana de Barcelona (1908-1958) entre d'altres, seguiran un procés similar de gestió en la seva apertura.

\subsubsection{Lisboa: Avenida da Libertade 1879-82}

Després del terratrèmol de 1755 Lisboa és reconstruïda seguint un precís plànol de E. Dos Santos i C. Mardel. El nou barri de la "Pombalina" pren el seu nom del Marques de Pombal, el seu impulsor. Es tracta d'un projecte de reforma de base geomètrica regular similar als "borgos" de Trieste. Un cop desenvolupada la reconstrucció de "la Baixa" es plantegen nous models d'ocupació pels territoris de topografia menys plana situats al nord del casc. El nou recurs seran les avingudes que ocuparan la part baixa de les valls immediates al nord de la Pombalina. El barri és denominarà "Avenidas Novas".

El primer projecte i que determinarà la nova forma i estructura urbana de Lisboa és el projecte per a la Avinguda da Liberdade, de F. Ressano Garcia de 1879. El projecte parteix d'uns jardins quasi privats de forma rectangular existents al nord de la ciutat, convertits posteriorment en parc o "passeio público" plaça "de los Restauradores". La seva apertura i perllongament convertiran aquesta avinguda en una de les més amples mai construïdes. Els 89,5 m d'ample superen clarament els $80 \mathrm{~m}$ dels Champs Elissees de París, l'avinguda de referència. L'avinguda es torça lleugerament a ponent respecte

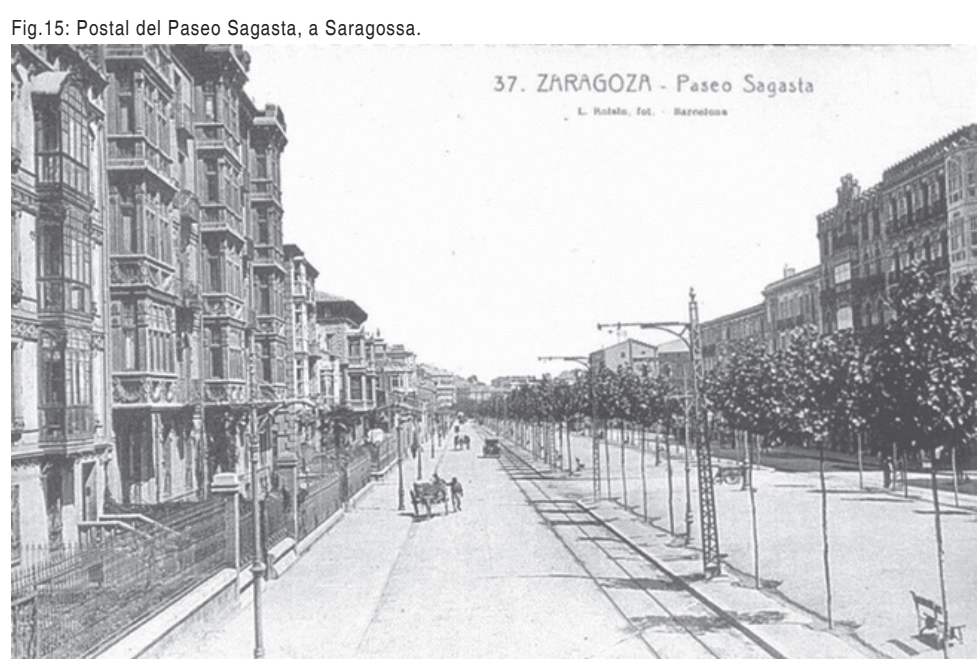

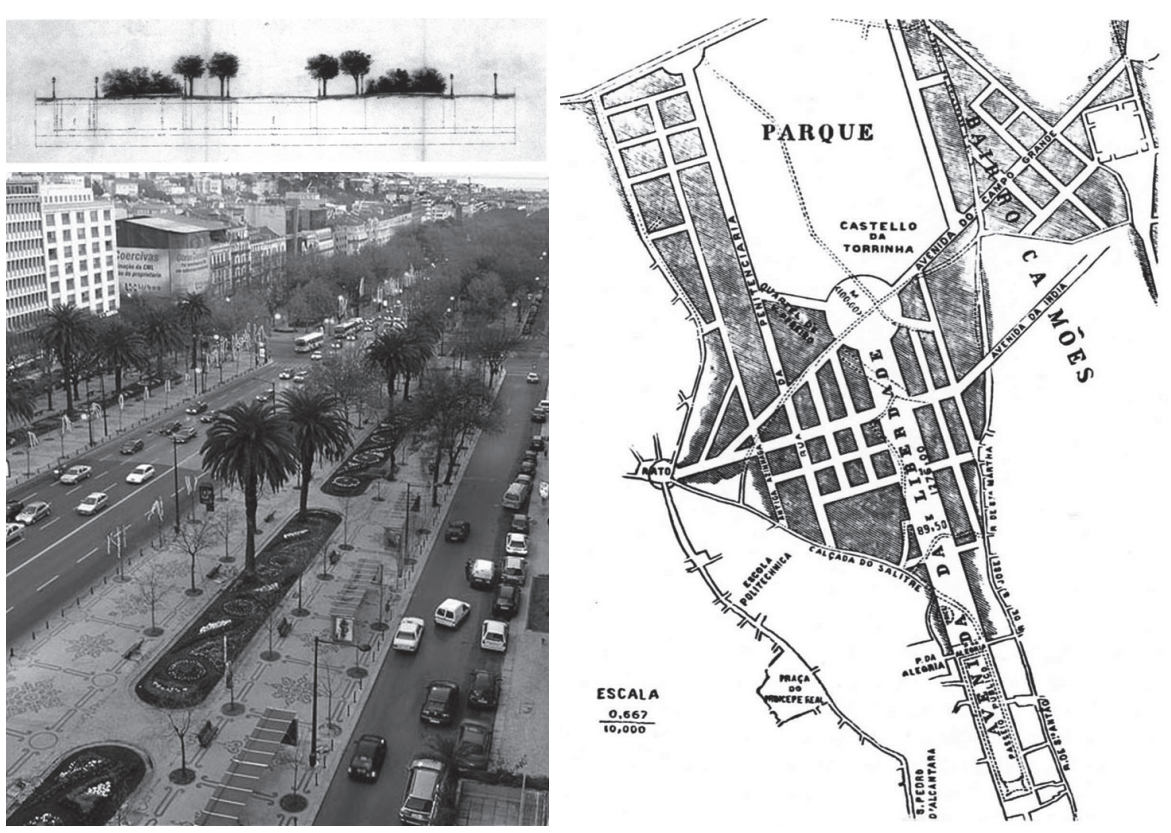

Fig. 16: Projecte i vista de la Avda Da Liberade de Ressano.

el traçat de la "baixa", seguin la geometria dels jardins existents. Tot el nou creixement s'ordena a partir de la seva traça amb vials paral.lels i ortogonals de menor secció. El creixement cap a llevant s'ordena a partir de les noves avingudes com l'Avinguda de Campo Grande o l'Avinguda de l'Índia.

L'avinguda da Liberdade no és excessivament llarga, amb $1.276 \mathrm{~m}$, semblant al passeig de Gracia de Barcelona. Com acabament té una gran plaça circular de $200 \mathrm{~m}$ de diàmetre, un xic menor que la plaça Etoile de Paris, que dóna accés a un gran parc (avui Eduard VII) al seu final.

La via es planteja com una gran avinguda: àmplia calçada central de circulació de $20 \mathrm{~m}$, dos grans passeigs per a vianants de $24 \mathrm{~m}$ amb tres rengles d'arbres, a cada costat, dues calçades laterals de circulació local de $6,75 \mathrm{~m} \mathrm{i}$ dues voreres de $4 \mathrm{~m}$ a tocar dels edificis.

La nova avinguda serà un èxit i la ciutat el prendrà com a futur model de creixement. Sobre el seu front s'hi situarà el nou habitatge burges i importants edificis terciaris i empresarials, desplaçant la centralitat de la ciutat cap la nova Avinguda da Liberdade.

El 1897 es presentarà el projecte de l'Avda. Das Picoas i el 1900 de l'Avda. Dos Anjos, com extensions cap el nord de Lisboa. 
Segons José-Augusto França la seqüència de les avingudes es:

- El 1888 F. Ressano fa els plànols per "Avenidas Novas".

El 1900-1903 avda. D. Amelia (avui Almirante Reis)

-El 1904 s'aprova el Plano Geral de Melhoramentos, que inclou las Av. Novas.

- El 1943 avdes. A.A. Aguilar i Sidónio Pais.

El 1954 avda. dels Estats Units.

El 1954 projecte avda. Infante Santo.

Els Plans Directors d'Urbanització que es redactaran per Lisboa (1938-49 i 1967-76) reforçaran les avingudes com a primera opció d'ordenació i estructuració del creixement.

\subsubsection{Altres plans d'avingudes}

Altres ciutats com Oporto optaran també per les avingudes. El creixemen d'Oporto sobre sistemes lineals dóna lloc a un creixement suburbà en els ravals del voltant del centre històric amb la conformació d'uns importants fronts edificats que genera uns importants jardins posteriors en el habitatges i s'implanten uns grans jardins interiors en les mançanes irregulars resultants de la superposició dels traçats. A principis del segle XX es construeix l'avda. Dos Aliados com operació de millora urbana a l'àmbit central.

La tradició moderna de les avingudes comença amb la Avda. Boavista, amb projecte de 1854. El traçat es desenvolupa en direcció a l'oest de la ciutat amb

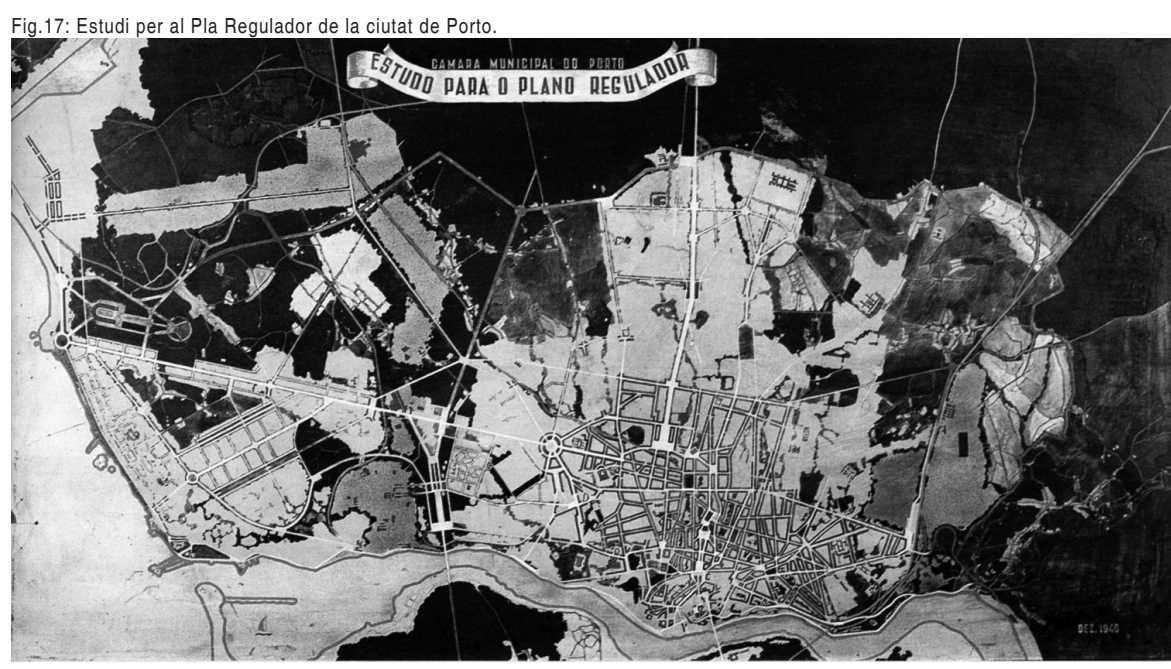

una amplada d'aproximadament $25 \mathrm{~m}$ en el tram central. Actualment té gairebé $7 \mathrm{~km}$ totalment rectes.

L'interessant proposta de Cunha Moraes de 1916, a la que hi va col.laborar també Barry Parker, publicada com "Os Melhoramentos da Cidade. Oporto", segueix apostant per un sistema d'avingudes especialment cap l'oest de la ciutat. La traça principal és una avinguda paral.lela i al sud de l’avda. Boavista. Al centre es complementa amb un curta i ampla avinguda nord sud de reforma interior que segueix en part l'esquema de la avda. Da Liberdade de Lisboa. Cunha segueix el dictat de Stubben proposant una via recta ja que es tracta d'una via de gran circulació.

“... Largas avenidas, arborisadas; boulevards, para grande circulação; passeios públicos de configuração irregular, com logares de repouso e de silencio, ruas de comercio, com bem iluminadas exposiz̧ōes; travessas, de prédios de modesto aluguer; ruas tranquilas, de casas particulares; ruas de luxo, ostentando habitaçôes com jardim á frente: eis os requisitos para uma cidade com aspecto de vida, verdadeiramente moderna."

El Plano regulador de la ciutat do Porto de G. Muzio de 1939-43, mostra una estructuració de tota la periferia d'Oporto en base a un precís traçat d'avingudes rectilínies que articula els principals creixements al nord i a l'oest.

Sao Paulo seguirà el model d'avingudes amb la construcció de l'Avda. Paulista de J.G. da Lima. Es tracta d'una via de promoció immobiliària de 2.800 $\mathrm{m}$ de longitud i $38 \mathrm{~m}$ d'amplada, que es convertirà en la arteria principal de la ciutat. Inicialment era un espai per a torres i palaus residencials. Avui dia l'avinguda està ocupada pels principals edificis terciaris de la ciutat.

El 1930 l'arquitecte, enginyer i polític F. Prestes Maia realitzarà una àmplia proposta d'avingudes focalitzades sobre una ronda central, seguint els patrons proposat per E. Henard per París.

Montevideo, a partir del traçat de la colònia espanyola fundada el 1726 , realitzarà un creixement basat en unes avingudes perfectament traçades sobre els careners de la rodalies, ordenant tot el creixement en relació a les noves avingudes. El primer pla d'extensió de la ciutat colonial de J.Ma. Reyes, de 1829-36, planteja un creixement en quadrícula que es recolza en un carrer central principal de $25 \mathrm{~m}$ (Avda. 18 de Julio). A partir d'aquí els successius projectes es basaran en sistemes jerarquitzats amb avingudes principals que suportaran els traçats.

El 1872 es determina una nova extensió en mançanes de la ciutat i el 1878 que la nova extensió (La ciutat novíssima) acabaria amb una avinguda de 50 m d'amplada (Bulevard Artigas) i el carrer Javier Barrios. 
El 1896 es realitza un "Plan de embellecimiento y ensanche de Montevideo" redactat per E. André que es basa en un conjunt de places i parcs units per un conjunt de vies parc.

El 1911 es planteja el concurs de les Avenidas per la nova extensió de la ciutat. Es molt interessant la proposta de E. Baroffio, que posteriorment serà un tècnic municipal molt important a la ciutat. El 1912 s'aprova el "Plan regulador de la ciudad de Montevideo" que recull les idees principals del concurs i altres criteris del jurat. Un nou pla de l'enginyer J.P. Fabini s'aprova el 1928. A partir de 1930 la ciutat adoptarà els criteris d'ordenació oberta.

La ciutat de Saragossa, a partir del Passeig de Santa Engràcia, (avui de la Independència) iniciat el $1833 \mathrm{amb}$ una servitud d'arquitectura, realitzarà un creixement basat en una àmplia proposta d'avingudes que articularan els nous teixits urbans. Seguiran el passeig Sagasta, entre la porta de Santa Engràcia, a la confluència amb el riu Huerva, i el Canal Imperial d'Aragó, és perllongarà cap el munt del Torrero. Era un passeig fora muralles al mig de camp, amb dues traces rectilínies, amb algunes edificacions residencials, industrials i col-legis. Era el "passeig de Gracia" de Saragossa. El 1900 s'urbanitza per convertir-lo en una via urbana.

El "Plano geométrico de Zaragoza" de $1861^{28}$ de J. De Yarza proposa una petita extensió al sud de la ciutat i la realineació de tots els àmbits edificats tal com determinava la legislació. És significativa la proposta d'una via ortogonal a l'actual Passeig de la Independència en el seu extrem sud d'un ample equivalent.

L'avantprojecte d'Eixample de la ciutat de Saragossa de D. Casañal i E. Burbano de 1906, és en realitat un projecte d'avingudes, amb un bulevard transversal on es suporten petits creixements en forma d'eixample amb unes mançanes força irregulars i de dimensió molt variable. Parteix un cop més del final del passeig de la Independència, que es prolonga amb la Avda. de la Llibertad (que no es realitzarà) i el Passeig Sagasta. També es proposaran altres avingudes a est i a oest. Transversalment es proposa, com si es tractés d'una de ronda intermitja, una via anomenada "Grandes Bulevares", per sota la traça del ferrocarril, que tampoc es desenvoluparà. Tot i això el model d'avingudes s'anava imposant.

El 1908 l'arquitecte R. Magdalena fa una proposta de petit eixample al voltant de la nova plaça de los Sitios.

El 1920 es cobreix el riu Huerva donant lloc a la Gran Via (1928-32) i, en una segona fase, al passeig de la Constitució, també sobre el riu. Sobre els nous vials es va recolzant el creixement urbà de la ciutat.
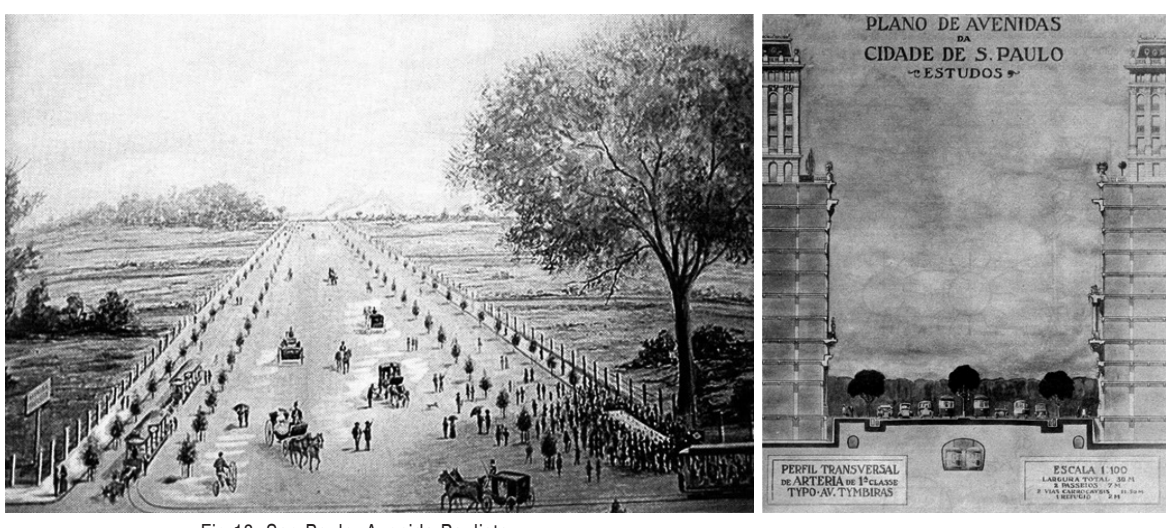

Fig. 18: Sao Paulo, Avenida Paulista

El Pla d extensió de 1930, abans anomenat d'eixample, es proposa amb zonificació i amb desenvolupament per polígons. Es basa en la prolongació del Passeig de la Independència, semblant a un bulevard, en $1,5 \mathrm{~km}$ amb una amplada de $40 \mathrm{~m}$.

El Pla general d'eixample de 1934 de M.A. Navarro recull la major part del traçats previst al pla de $1930 \mathrm{amb}$ la incorporació de la Zona Universitària una ciutat jardí. Comprenia Miralbueno amb 141 ha i 28.000 hab.; Miraflores amb 88 has i 17.000 hab. i un àmbit de ciutat jardí per a la construcció de 500 cases barates, que provenia d'un projecte de 1928 de Zuazo, Ribas i Navarro per a la Societat Zaragozana d'Urbanització i Construcció .

L'Avantprojecte d'Ordenació general, aprovat el 1942 proposava l'avda. Imperial que donaria lloc amb diferències a l'avda Cesaraugusto i la prolongació del Passeig de la Independència que tampoc es desenvoluparia. Més tard es va proposar la reforma de l'eixample Miraflores que es va adoptar.

J. Yarza proposa el 1950 l'avda de los Héroes, projecte gairebé monumental, que es recollirà en el seu Pla de 1957 i que donarà lloc a l'avda. del Pirineus.

\subsection{Els "rings" o rondes}

A diferència dels eixamples, que plantegen creixements il-limitats, els projectes de rondes o "rings" plantegen creixements limitats amb anells concèntrics a la ciutat antiga o bé la reforma d'espais intersticials com en el cas de Viena. En molts casos són el resultat d'intervenir sobre l'espai que ocupaven les antigues muralles i el glacis de la ciutat, un cop enderrocades majoritàriament durant el segle XIX i principis del XX. Els eixamples resolien molt bé les qüestions relatives al creixement, en canvi els rings o rondes són projectes de menys dimensió i, per tant, més limitats respecte al sòl de creixement. Tot i 
aquesta limitació els projectes de "rings" o rondes aporten, en general, una proporció molt més gran d'espais públics i equipaments que els eixamples.

Aquesta forma de traçat és recolza en un gran vial anular força llarg i ample que a més de resoldre l'estructura interna del nou àmbit de creixement, complementa i dona servei a l'escassa vialitat del centre històric. La nova ronda o "ring" juga un triple paper: vialitat estructurant del nou creixement, vial de reforç de la ciutat antiga especialment pel que fa al transport col-lectiu, i en molts casos d'emplaçament dels nous equipaments i dels nous jardins o parcs urbans de la ciutat.

Fonamentalment hem seleccionat aquells traçats que porten associat creixement urbà, fent només esment als casos on la ronda o "ring" és una simple operació de substitució de muralla i glacis per ronda o "ring" sense creixement urbà associat.

Són molt significatius el "Ring de Viena" i el "Ring de Colònia", ambdós amb un important creixement urbà associat. El sistema de ring té una gran tradició a les ciutats de l'Europa central. També seria molt interesant, si s'hagués realitzat, com a projecte de ronda o "ring" la proposta per l'Eixample de Barcelona d'Antoni Rovira i Trias, guanyador del concurs convocat per l'Ajuntament de Barcelona el 1859. Per qualitat i sobretot per extensió seria el més important de tots ells.

El model de ronda o "ring" fins i tot s'utilitza en el projecte de traçat en alguna intervenció de reforma de la trama urbana existent com és el cas del Gran Bulevard de Budapest.

\subsubsection{Rings precursors}

El Plan Général d'agrandissement de la Ville de Geneve de 1855. L'inici de la demolició de les grandioses muralles de Ginebra és de 1850 i s'acaba el 1851. Poc després el 1854 es proposa un Pla d'extensió amb nous traçats viaris rectes. El traçat inicial es modifica el 1855 i es torna a modificar definitivament el 1858. Les dues modificacions tenen l'aprovació del Consell d'Estat. Es tracta d'un projecte realitzat per l'enginyer cantonal L.P. Blotnitzki ${ }^{29}$ a la escala de 1:4.000. La proposta abasta principalment els terrenys de la muralla i glacis i dobla l'extensió de la ciutat.

El Pla consisteix en un creixement concèntric al casc antic, suportat per uns bulevards o rondes d'entre 25 i 30 m d'ample que el circunval.len. Hi ha un sòl traçat de la ronda a ponent i a sud (Rue de Conseil Général i Boulevard des Philosophes), però a llevant el traçat te tres desdoblaments, dos d'ells

$29 \mathrm{~A}$ partir de 1855 és construeixen nous barris de traçat ortogonal amb noves places, nous ponts (el del Mont-Blanc de 1861 i el de la Coulouvrenière de 1857) i cinc nous edificis religiosos (ceinture fazyste) sobre terrenys oferts per l'estat. La ciutat passa de 31.238 habitants a 52.043 i els municipis suburbans de 6.486 a 13.666 habitants.

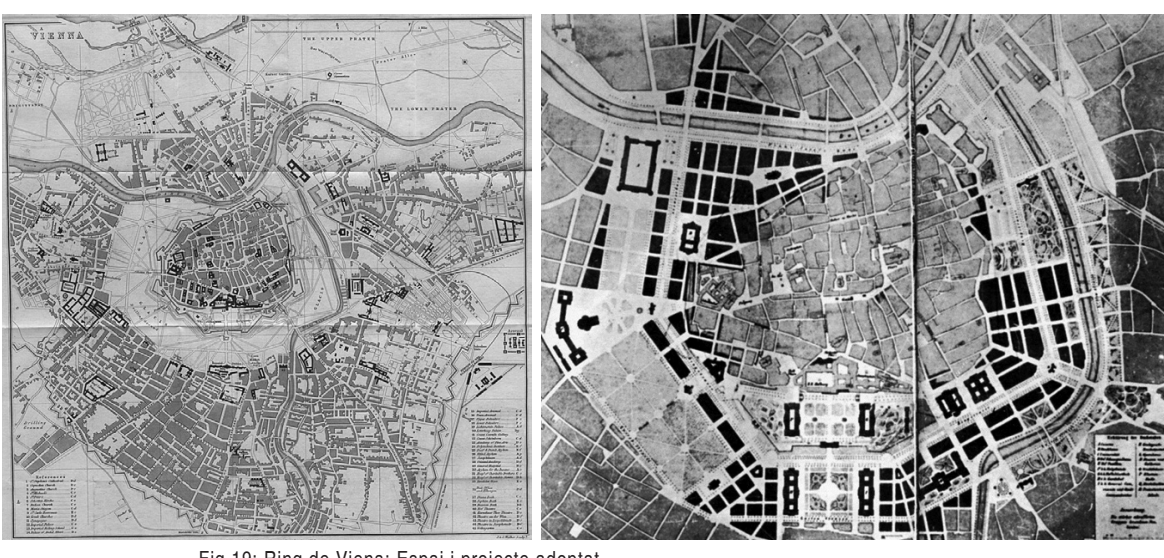

Fig.19: Ring de Viena: Espai i projecte adoptat.

de força continuïtat (Bd. Dalcroze i especialment el Bd. Helvétique). Amb l'eixamplament posterior del pont del Mont-Blanc sobre el llac Leman es tancarà l'anell per la part nord. La proposta incorpora un conjunt de parcs jardins situats en continuïtat a la ciutat antiga, com el Parc dels Bastions on s'hi edificarà la Biblioteca de la ciutat.

\subsubsection{El projecte del Ring de Viena de 1858}

La ciutat havia tingut el primer i molt fort setge turc el 1529. El segon es produeix el 1683 . Com mesura preventiva es va mantenir la muralla de la ciutat antiga amb un immens glacis d'uns $500 \mathrm{~m}$ d'amplada dins el nou creixement de la ciutat i les darreres muralles (Linienwall), iniciades el 1704 ampliades el 1850 i finalment enderrocades a partir de 1894. L'espai defensiu de la primera muralla i glacis era d'unes 200 ha, una superfície semblant a la del casc antic de Barcelona.

El 1857 s'enderroquen les muralles interiors i el 1858 es convoca un concur internacional per al projecte del Ring de Viena. El concurs tingué gran ressò Es varen presentar un nombre molt elevat de propostes. Atesos els diferents valors parcials dels projectes guanyadors, el govern va decidir anomenar una comissió formada pels tècnics del ministeri i els redactors dels tres projectes guanyadors (1er L. Foster, 2on F. Stache, 3er A. S. v.Sicarsdburg i E.v.d. Nüll) dirigits per M.R.v. Loehr que van formular una excel-lent proposta conjunta que constava de:

Un "ring" o bulevard continu amb nou trams, que connectava amb el canal dret del Danubi per ambdós costats. La traça es situava en el punt mig del buit urbà, el que permetia crear nous fronts a tots dos costats. El Ring tenia $4.050 \mathrm{~m}$ (5.200 m incloent el front fluvial) de longitud i una amplada de 57 


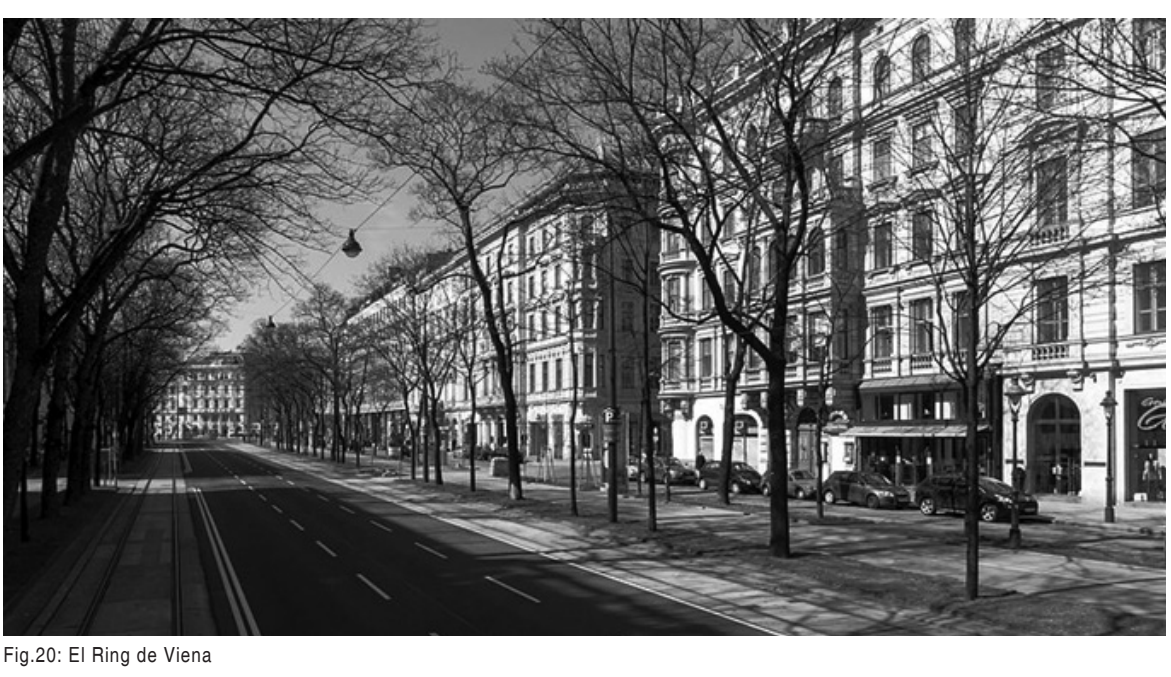

$\mathrm{m}$, molt semblant al passeig de Gràcia de Barcelona. La secció era en realitat d'avinguda amb una calçada central de $15 \mathrm{~m}$, dos passeigs laterals de $8,5 \mathrm{~m}$ amb dos rengles d'arbres, dues calçades laterals de $6,5 \mathrm{~m}$ i dues voreres de $6 \mathrm{~m}$.

_ L'ordenació constava, en el tram central, de tres grans grups d'equipaments i edificis públics articulats pel Ring i un important conjunt de places i espais públics. Es completava amb un parc, una vintena d'equipaments i un gran nombre de petites places i jardins. Els elements públics s'acompanyaven amb uns teixits residencials formats per carrers ortogonals als cinc grans trams rectes en que es descomponia el traçat del Ring i per mançanes de geometria regular. El projecte tindrà petits canvis no substancials durant el seu desenvolupament.

Com veurem també a Colònia les rondes de Viena queden a un sol costat del Danubi i, per tant, no el travessa. Aquesta és una opció usual atès l'elevat cost de construir ponts en rius d'aquesta importància.

Les mançanes destinades a habitatges burgesos seran de reduïdes dimensions i no generaran pati interior de mançana. El parcel.lari regular i molt ben ordenat donarà lloc a un interessant habitatge burges que es desenvoluparà al llarg del nou traçat amb una tipologia basada en uns patis interiors que cada edifici anirà envoltant perimetralment per crear noves façanes interiors complementàries a les dels carrers. Les altures ordinàries eren planta baixa i $4 / 5$ plantes pis.

El Ring de Viena es convertirà en un projecte de referencia en el camp de l'urbanisme a la segona meitat del segle XIX. El fet de que sortís publicat a doble pàgina en el manual "Der Städtebau" de J. Stübben de 1890 va ajudar a la seva difusió. En el cas de Barcelona es va considerar una oportunitat perduda el no

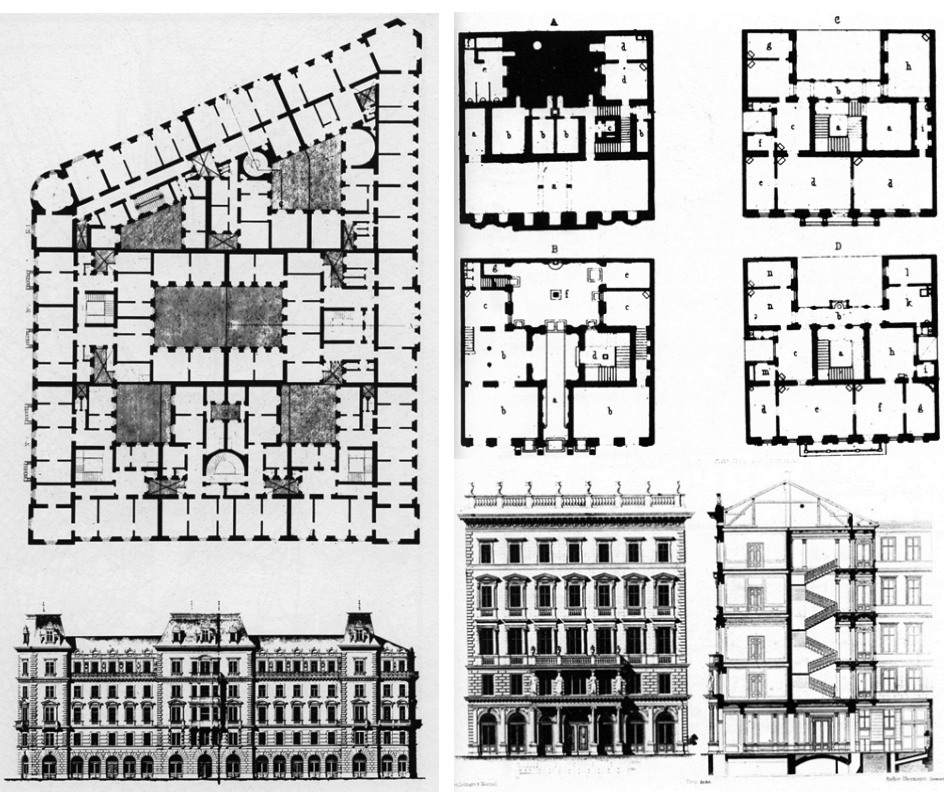

ig. 21: Mançanes i habitatges, Vien

utilitzar una solució similar a la de Viena per resoldre la trobada del Pla Cerdà amb la ciutat antiga aprofitant els terrenys i glacis de les muralles.

Un segon anell el Wiedner Gurtel és va construir al costat de les darreres muralles de la ciutat (Linienwall). Otto Wagner va realitzar el 1910 una interesant proposta de creixement per Viena basada en rondes i districtes.

\subsubsection{El projecte del "Ring” de Colònia de 1881}

Uns anys després, el 1881, J. Stübben i K. Henrici s'encarregaran de realitzar el projecte pel "Ring" de Colònia. La ciutat finalment havia aconseguit comprar els terrenys al govern de l'estat desprès d'una llarga negociació entre 1860 i 1880 per 12 milions de marcs. Les relacions entre les grans ciutats i l'Estat sempre han estat tenses quan hi ha propietats pel mig.

El projecte consta d'un bulevard d'onze seccions diferents, una per cada tram recte. Això és bastant original. La varietat espacial de cada tram li dóna una gran singularitat. La longitud és de $5.930 \mathrm{~m}$. Les amplades oscil.len entre 32 i $128 \mathrm{~m}$.

La superfície ordenada no era molt gran (unes 425 ha) ja que la nova extensió també havia de gaudir de muralles. L'amplada del nou creixement oscil.la entre 500 i $800 \mathrm{~m}$. 
El "ring" o bulevard es situa molt a prop de casc antic, creant una petita illa entremig. Hi ha una gran continuïtat entre les vies del cas antic i el nou traçat. Quasi tots els carrers de l'interior tenen continuïtat a traves del nou traçat, més enllà del "ring" o ronda.

El projecte planteja, a més de la diversitat dels diferents trams, un conjunt important d'espais i edificis públics. En total són uns 14 punts nodals. També es localitzen en el nou àmbit dues estacions de ferrocarril.

Els onze trams són:

- Ubierring I de forma triangular amb 76 m d'ample mitjà i de 250 m de longitud. Té un parc central.

- Ubierring II de $32 \mathrm{~m}$ d'ample i de $275 \mathrm{~m}$ de longitud. Té un passeig central de $9 \mathrm{~m}$.

- Karolingerring de $34 \mathrm{~m}$ d'ample i de $250 \mathrm{~m}$ de longitud.

- Sachenring de $72 \mathrm{~m}$ d'ample i de $800 \mathrm{~m}$ de longitud. Té un passeig-parc central de $35 \mathrm{~m}$.

- Salierring de $40 \mathrm{~m}$ d'ample i de $500 \mathrm{~m}$ de longitud.

- Hohenstaussenring de $36 \mathrm{~m}$ d'ample i de $650 \mathrm{~m}$ de longitud. Té un passeig central de $9 \mathrm{~m}$.

Habsburgerring de $36 \mathrm{~m}$ d'ample i de $200 \mathrm{~m}$ de longitud. Té un passeig central de $15 \mathrm{~m}$.

- Hohenzollerring de $36 \mathrm{~m}$ d'ample i de $700 \mathrm{~m}$ de longitud.

- Kaiser-Wilhem-ring de 62,3 m d'ample i de $350 \mathrm{~m}$ de longitud. Té un passeig-parc central de $35 \mathrm{~m}$.

- Hansaring de 40,5 m d'ample i de $1.100 \mathrm{~m}$ de longitud. Té un passeig central de $15 \mathrm{~m}$.

- Deutscherring (Theodor-Heuss-ring avui) de $128 \mathrm{~m}$ d'ample i de $675 \mathrm{~m}$ de longitud. Té un parc central de 83,5 m d'ample.

En realitat són deu directrius geomètriques diferents que comencen i acaben sobre el passegi fluvial de la ciutat (Konrad Adenauer-Uter). Pel que fa a les longituds dels trams: cinc trams tenen entre 200 i $350 \mathrm{~m}$; cinc entre $500 \mathrm{i}$ $800 \mathrm{~m}$ i nomes un $1.100 \mathrm{~m}$. Les amplades dels diferents trams son: 32; 34; 36 ; 40; 40,5; 62,3; 72; 76 i $128 \mathrm{~m}$. El que dona una amplada mitjana ponderada de $56 \mathrm{~m}$

Pel que fa a les seccions té tres trams (amb amplades de 34, 36 i $40 \mathrm{~m}$ ) amb secció d'avinguda (calçada central i amplies voreres); altres quatre trams (amplades 32, 36 i 40,5 m ) tenen passeig central o rambla de 9 ó $15 \mathrm{~m}$; dos trams (amplades 62,3 i $72 \mathrm{~m}$ ) tenen un gran passeig-parc de $35 \mathrm{~m}$ i els dos trams inicial i final tenen un parc central. L'ample mínim de $32 \mathrm{~m}$ permet
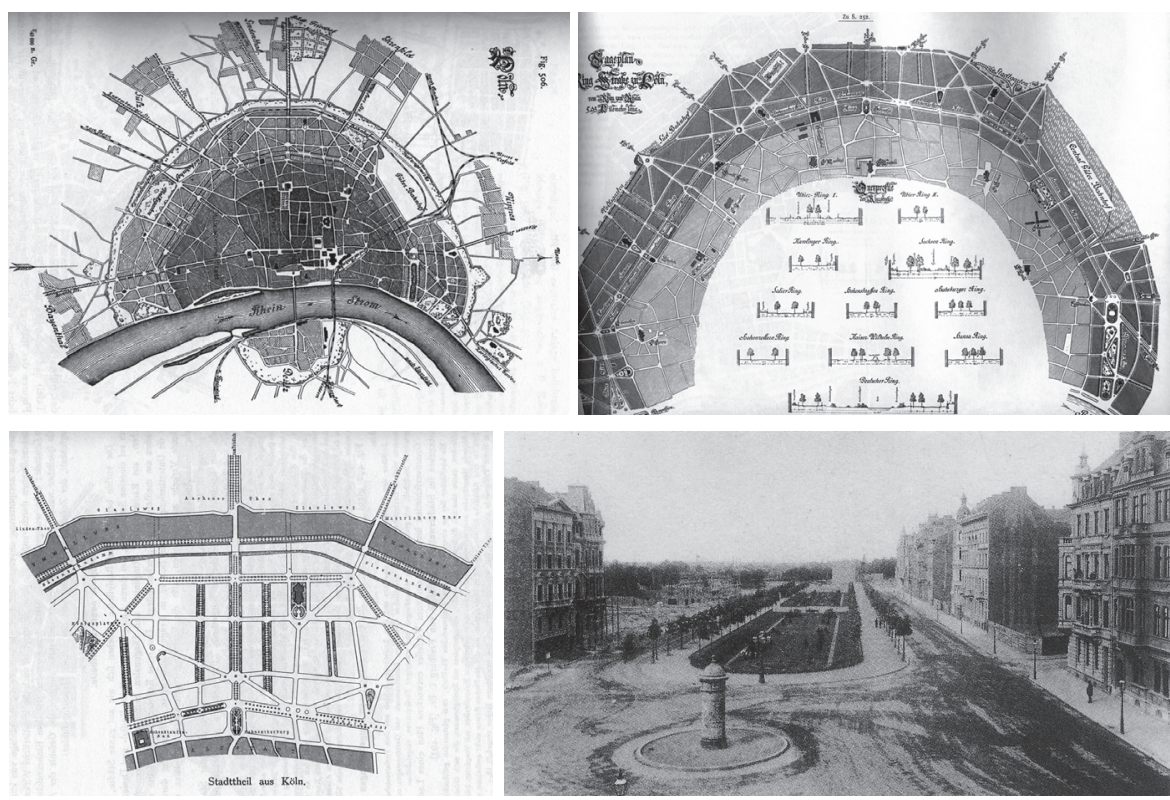

Fig. 22: Ring de Colònia (Alemanya).

utilitzar tant la secció d'avinguda amb grans voreres com el passeig o rambla central. Fins als $40 \mathrm{~m}$ d'ample les dues opcions s'utilitzen indistintament. Entre els 62 i els $72 \mathrm{~m}$ d'ample s'utilitza només el model de passeig-parc central amb una ample de $35 \mathrm{~m}$. Per sobre d'aquests valor es localitza un parc central de grans dimensions.

La seqüència dels onze trams és: parc-passeig-avinguda-passeig/parc-avinguda-passeig-passeig-avinguda-passeig/parc-passeig-parc, només un cop es repeteix la secció, normalment es van alternant.

El model de "ring" es consolidarà en el futur urbanístic de la ciutat a ponent. La segona ronda paral-lela es consolidarà a un kilòmetre de la primera. La tercera ronda (gurtel) sortirà a una distància similar de la segona i la quarta ronda mantindrà també una distància similar a la part sud separant-se a la part nord. Fins i tot les modernes autopistes de ponent segueixen un traçat paral.lel al primer "ring". A llevant la ciutat no seguirà aquest model de rondes per la dificultat de travessa del riu Rihn.

Els habitatges burgesos alineats al carrer i construïts entre mitgeres deixaran patis que aniran absorbint el caràcter triangular del teixit urbà resultant. Els edificis del Ring tenen una interesant ordenança de PB i 4 plantes a les que cal afegir un àtic que es manté vigent a l'actualitat i li dóna un gran valor de continuïtat. 


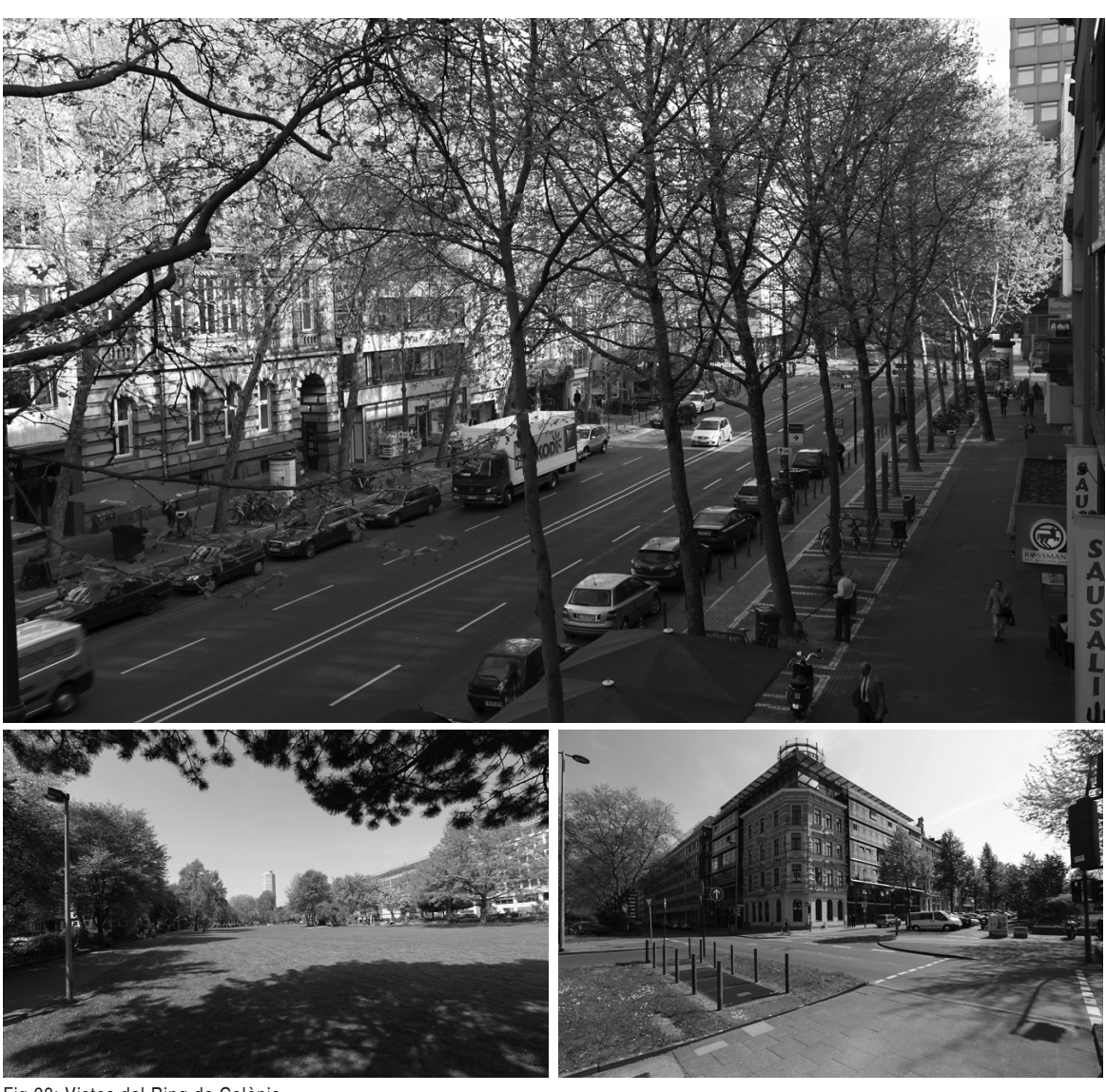

Fig.23: Vistes del Ring de Colònia

\subsubsection{Altres projectes de Rings}

\section{Rings amb creixement}

Els Ring de Szegedin de 1880 de J. Stubben. La ciutat de Szeged, avui hongaresa, havia sofert una important inundació el 1879 pel desbordament del riu Tisza. Dels 5.723 edificis existents només van quedar drets 265, van morir 165 persones. L'Emperador Franz Joseph va prometre una ciutat encara més maca del que havia estat, amb amplis carrers. A la reconstrucció de Szegedin J.Stübben proposa una solució molt similar a la de Colònia però amb dues anelles. L'interior de gairebé $30 \mathrm{~m}$ i l'exterior de $35 \mathrm{~m}$ d'ample.

El Ring de Düsseldorf de 1884. Aquest tipus de traçat amb ring o ronda es planteja a Düsseldorf (1884) per Conrath, Meyer i Sübben amb molta més longitud de l'habitual, però amb una molt menor secció.
El Ring de Brussel-les. El Ring de Brussel-les té origen en les rondes que es van situar en l'espai que ocupaven les antigues muralles enderrocades entre $1810^{30}$ i 1840 . A partir d'un Pla de François Verly de 1817 es planteja la reconversió parcial de les muralles en rondes per relacionar millor el centre amb els suburbis ${ }^{31}$. Tot i que el pla no es va aprovar el 1818 si que s'aprova un segon Pla de l'enginyer en cap J.B. Vifquain on es plantegen "...grans arteries arbrades que donin accés a les portes de la ciutat...”. Es comença a construir la ronda per trams: Boulevard d'Anvers el 1818, Boulevard de Waterloo el 1830, Boulevard de l'Entrepot a 1851. La urbanització de les rondes s'acompanya amb la redefinició de les portes d'entrada a la ciutat. Les rondes són una oportunitat per emplaçar els nous equipaments i institucions: l'Observatori el 1823, el Jardí Botànic el 1826, l'Hospital de Sant Juan, l'Hospital Pacheco el 1828, La Caserne de la policia el 1839, etc.

Amb la independència de Bèlgica el 1831 s'inicia una expansió de la ciutat a l'est de les rondes amb el Quartier Leopold projectat per T.F. Suys el 1838 El seguirà el Quartier Louise més al sud. A partir de 1843 és realitzaran plans per reordenar els suburbis de la ciutat. El $1862 \mathrm{~V}$. Besme realitza un pla d'envelliment i d'integració de la ciutat i els suburbis on es proposa una segona ronda exterior o Gran Ceinture.

Amb l'aprovació de les Lleis d'expropiació forçosa de 1858 i 1867 s'inicia una reforma interior amb la introducció de bulevards de menor dimensió que les rondes com ara el Boulevard central, avui Anspachlaan, de $32 \mathrm{~m}$ d'ample inicial, reduït finalment a $25 \mathrm{~m}$, obertura important dins el teixit medieval d'accés a la nova estació de ferrocarril del Midi.

La Petite Ceinture o Ring de Brussel-les deu haver estat reurbanitzat i sobretot replantat a partir dels anys $1850 \mathrm{amb}$ l'aparició del Macadam, aglomerat asfaltic, i molt probablement reformat en el període 1881-1899 quan és nombrat burgmestre Charles Buls.

El "ring" presenta sis trams diferenciats amb una longitud de $8 \mathrm{~km}$. Els més interessants són els trams situats a l'Est: el Bulevard de Waterloo, del Regent de l'Observació (avui Bischoffsheim), amb 54, 80 i 58 m d'amplades inicials respectivament. És una autèntica ronda de la ciutat antiga. Només a est es planteja una intervenció de creixement aprofitat el parc de Brussel.les, ja existent, com nexe d'unió.

Les rondes actuaran com a punt de distribució de les noves avingudes que ordenaran el nou creixement de la ciutat. El més efectiu és el tram del Regent que ordena tot un creixement de mançanes a l'est. Amb la nova ordenació es va reduir l'ample d'aquest tram de 80 a $60 \mathrm{~m}$. 


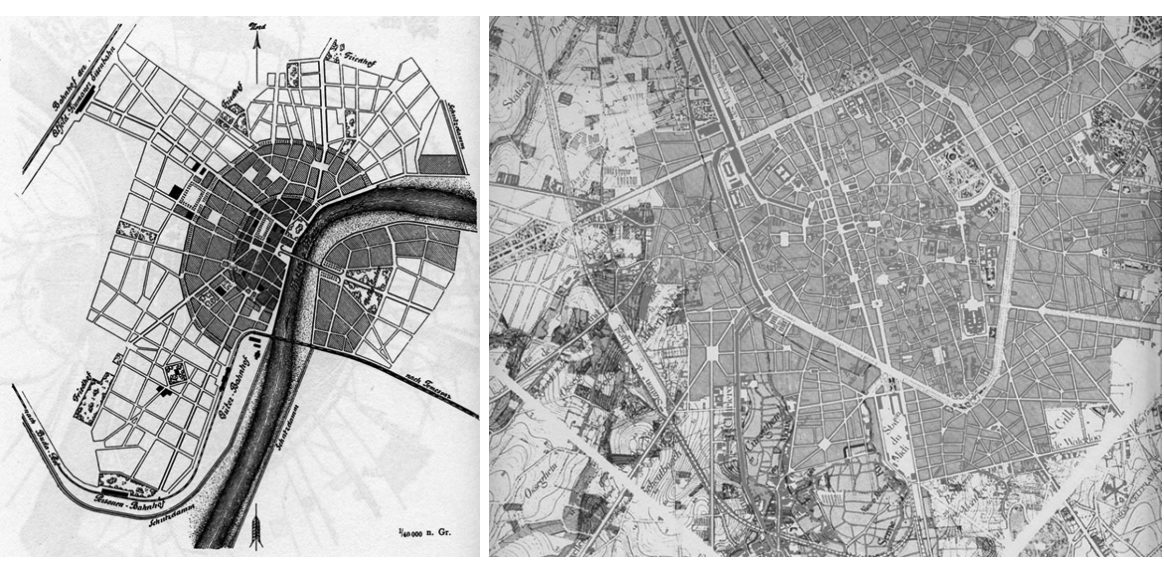

Fig.24: Ring de Szegedin i la Petite Ceinture de Brusel.les

El 1894 s'incorpora a les rondes la primera línia de tramvies elèctrics. L'any 1957 les rondes són transformades en vies especialitzades per facilitar el trànsit rodat. Són parcialment deprimides amb interseccions a dos nivells. Pateixen una important pèrdua espacial especialment per la presència de nombrosos passos inferiors. A partir de 1969 s'introdueix el metro a Brussel.les amb la utilització en part la traça de les rondes. El 2010 es determina una zona de velocitat $30 \mathrm{~km} / \mathrm{h}$ dins el Pentàgon.

\section{Rings de reforma sense creixement}

Moscou té un creixement tradicional basat en rondes. Les primeres rondes de Moscou ocupen les successives muralles que un cop enderrocades es converteixen en importants vies que es van ampliant en el temps. No tenen un traçat projectat ni tampoc ordenen el creixement ja que normalment quan s'urbanitza la ronda, la ciutat ja està edificada per ambdós costats. Destaquen les dues primeres de dins a fora: el "Bulevard Ring" (Bulvarnoye Koltso) i el "Garden Ring" (Sadovoye Koltso).

El primer -el Bulevard Ring- es va construir al lloc de les muralles al segle XVI.

El segon -El Garden Ring- és va iniciar cap el 1820 reemplaçant les segones muralles, té caràcter unitari i tanca el cercle complet. Té una longitud de 16 $\mathrm{km}$. El composen disset trams de carrer i quinze places. En el Pla de 1935 es va proposar el seu eixamplament fins a un mínim de 30 o $40 \mathrm{~m}$. Avui dia té un ample que oscil.la entre 50 i $80 \mathrm{~m}$. Quan es va iniciar la seva construcció, la ciutat ja havia crescut per la part exterior i, per tant, no és una ronda de creixement, sinó que és una via de cosit intern de la ciutat.
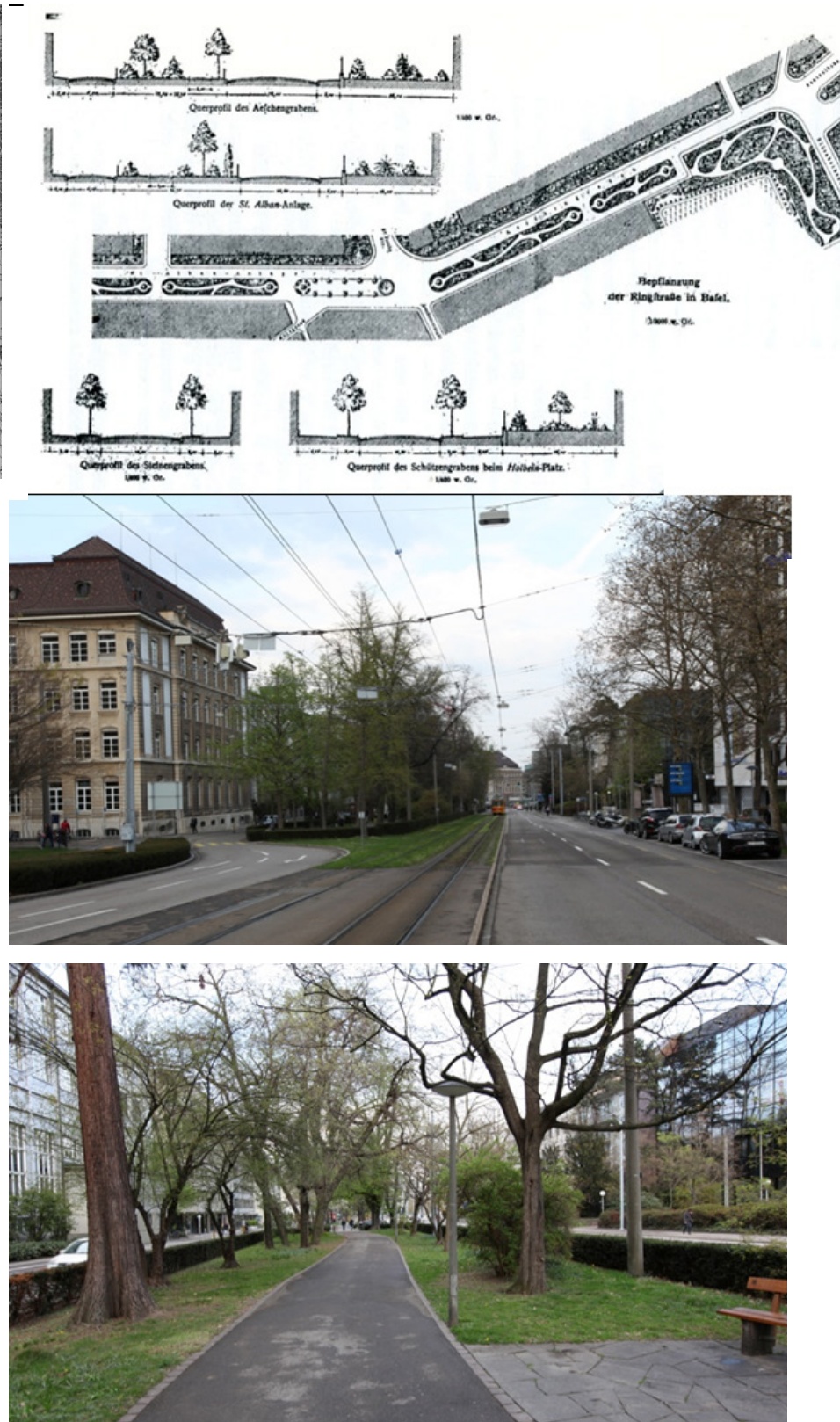

Fig.25: Projecte i vistes del Ring de Basilea.

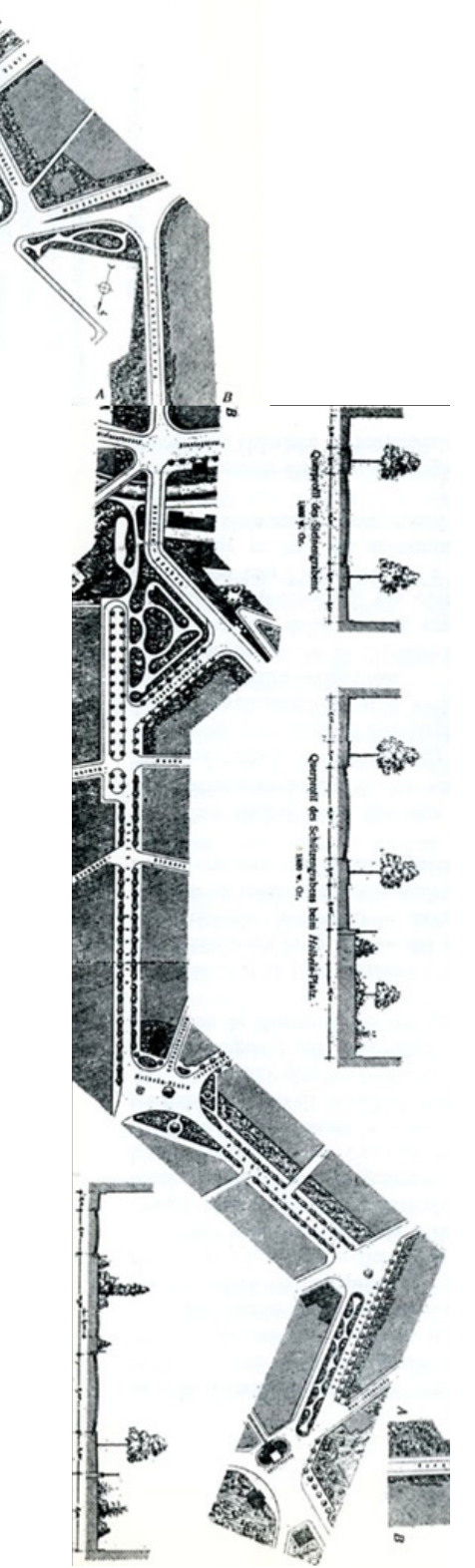


La tradició continua. Un tercer ring (Ulitsa o Transportnoye Koltso) es va completar el $2004 \mathrm{i}$ té les característiques d'una autopista. Un quart anell està en construcció i un cinquè el MKAD, realitzat el 1961, és per a trànsit rodat i coincideix amb els límits municipals de Moscou.

Budapest realitzarà el 1880 el seu "ring", el Nagykörut (Gran Bulevard) com pla de reforma sobre la trama urbana existent, tampoc comportarà nou creixement urbà. Té cinc trams ben diferenciats i una longitud de $4.150 \mathrm{~m}$. i un ample de $33 \mathrm{~m}$. El caràcter de la reforma aconsellava no utilitzar amples excessius per no perjudicar la gestió i encarir el cost. Tot i el nom de bulevard en realitat té una secció de carrer convencional amb una calçada central de $20 \mathrm{~m}$ i dues voreres arbrades de 6,5 m. En els extrems sobre el Danubi es proposaven dos grans ponts. Posteriorment l'anella es consolidarà a l'altre costat del riu.

\section{"Rings" - Viesparc}

Un gran nombre de ciutats, especialment alemanyes, realitzaran projectes de Rings en l'espai de les antigues muralles, mantenint en alguns casos la literalitat del traçat petri com en el cas de Bremen. Sovint el nou Ring es plantejarà com via parc com en el cas del Ring de Nuremberg, Breno, Frankfurt o Munich.

El "Ring" de Basilea de 1860. El projecte consisteix en un traçat de geometria molt complexa, segurament per l'estat avançat de la urbanització del sector. Té continus canvis de direcció així com seccions força diverses que van des de els 24 fins els gaire bé $81 \mathrm{~m}$ d'ample. És una via parc i genera creixement irregular amb mançanes. El tram més interessant és Aeschengraben, amb una secció de 53,5 a 56,8 m. que surt de l'estació i la seva prolongació St. Alban Anlage, amb una ample de $51,45 \mathrm{~m}$. Té un interesant passeig-parc de entre 15,4 i 18,7 m d'ample amb un pas sinuós per vianants de $3 \mathrm{~m}$. Un segon element verd de $15 \mathrm{~m}$. d'ample completa la secció. Avui pràcticament tota l'edificació està renovada.

El Ring d'Aachen de 1875. La ciutat d'Aquisgrà decideix el 1875 créixer més enllà de les muralles degut a les pèssimes condicions de vida a l'interior. La proposta de Ring es durà a terme a partir d'un projecte de K. Henrici. La Monheims Allee té diverses traces rectes i diverses seccions. El tram central, és un bulevard de $71,8 \mathrm{~m}$. d'ample amb un ampli passeig arbrat de $38 \mathrm{~m}$. Ordena el creixement de la ciutat en el tram de llevant.

El treball d'Henrici influenciarà molt Stubben. Posteriorment col-laboraran en diversos projectes, la major part "rings" a Colònia, Munich, Dessau, Brünn, Trier i Hannover.

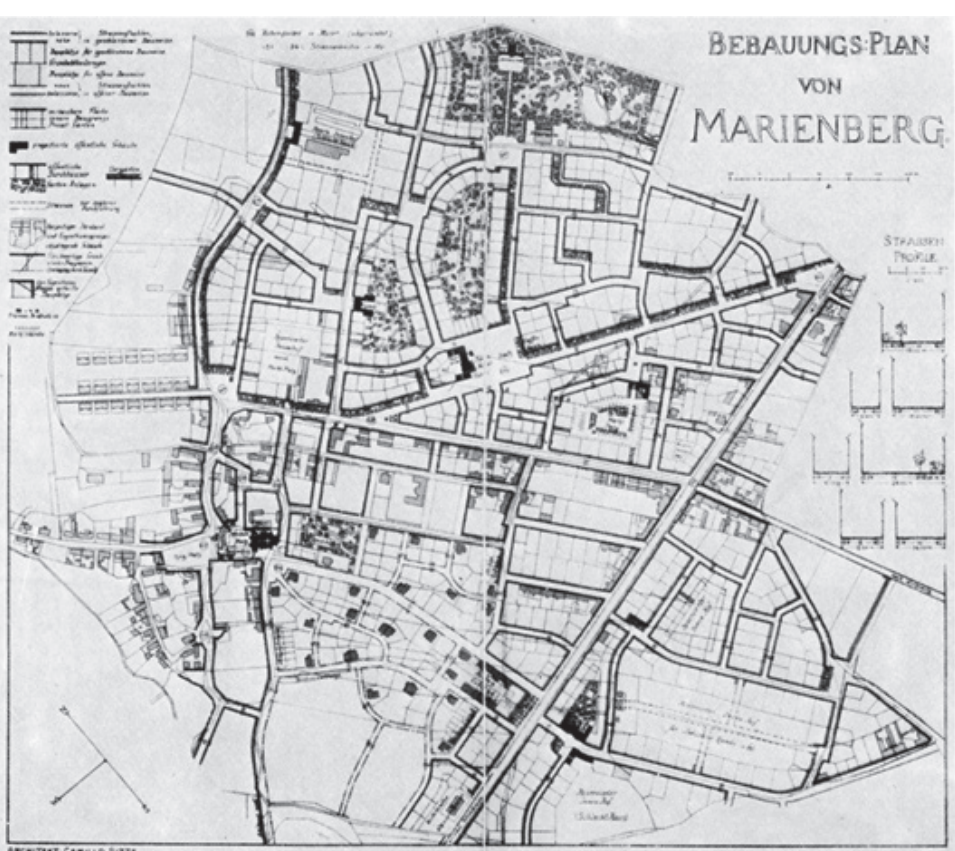

Fig.26: Projecte de Sitte per a Marienberg.

\subsection{Els traçats mixtes i l'urbanisme de paper de Camillo Sitte.}

Cap a final del segle XIX, especialment a Alemanya i a altres països del centre d'Europa, sorgirà una nova manera de fer ciutat, menys reeixida, però que prendrà força en els nous projectes d'extensió i reforma de les ciutats, sota la influència de Camillo Sitte ${ }^{32}$ i del seu tractat "Construcció de ciutats segons principis artístics" publicat a Viena el 1889. Aquesta influència perdurarà gràcies a la revista Der Staedtebau, que es publica a partir de 1904, on és publicaran nombrosos articles i projectes d'aquesta manera de fer ciutat, tot i la mort de Sitte el 1903.

El nou ideari surt com rebuig de la geometria rotunda, continua dels traçat anteriors: els eixamples, les avingudes i les rondes, i es proposa que aquesta geometria continua sigui substituïda per trams discontinus de vials que conflueixen en un sistema de places neomedievals on s'emplacin els nous edificis públics.

32 Camillo Sitte (1843-1903) nascut a Viena. Director de l'Escola d'Art industrial de Viena. Critica la pràctica tecnicista dels urbanistes alemanys. Publica el 1889 Der Stadtebau (Construccí de ciutats segons principis artístics) on analitza la ciutat medieval i es mostra partidari d'un model de ciutat basat en aquells principis. Dóna prioritat a la composicio front als aspectes funcionals. 
Els nous traçats incorporaran sistemes de composició urbana on la simetria i la focalització de edificis públics, juntament amb l'aparició d'importants espais públics, prendran gran importància. Els traçats ja no seran tan rectilinis. La línia recta serà substituïda per la poligonal i les mançanes seran cada cop menys quadrades i més allargades. Els edificis importants els situaran fent front als nous vials.

Hi ha un guany cívic en la nova proposta de ciutat però també una evident pèrdua de funcionalitat urbana. El retrocés en l'evolució de la construcció de la ciutat és gran. La sort és que pràcticament cap Pla urbanístic de mitjana o gran escala es realitzarà sota les noves idees de Sitte. Només les petites intervencions pintoresques lligades a renovacions urbanes al voltant dels monuments tindran en consideració l'ideari de Sitte. És representativa d'aquesta microcirurgia urbana la intervenció de J.Stubben davant l'església de Sant Pere de Lovaina.

Tot i el fracàs de l'urbanisme de Sitte els grans traçats del XIX deixaran pas a noves formes de fer ciutat, per bé que en alguns països com el nostre la influència dels eixamples perdurarà força durant el segle XX.

\section{EPÍLEG}

Malgrat els intents de crear noves ciutats i nous teixits urbans durant el segle $\mathrm{XX}$, la ciutat del XIX es mostra com hegemònica, com el paradigma de la ciutat actual: compacitat, gran densitat, barreja d'usos, flexibilitat... Més actualitat gairebé impossible.

A més, en la majoria de les ciutats, aquesta ciutat amb traçat s'ha convertit en l'autèntic centre de la nova metròpoli, acollint moltes de les activitats i les seus centrals de les companyies financeres, de les grans empreses i de l'administració.

La gran vialitat aportada en el projecte i la implementació d'un sistema de transport col-lectiu potent els ha convertit en un gran centre urbà, on la compra i l'esbarjo, ocupen aquestes les plantes baixes dels principals carrers de la ciutat i de vegades edificis sencers.

Un aspecte interessant és que, degut a un renovat habitatge de gran dimensió, els traçats es van convertint en barris residencials molt apreciats per la ciutadania.

Avui en dia mantenen un equilibri entre treball i residència, i això dóna lloc a una part de la ciutat molt viscuda a tot hora i amb un gran control socia de l'espai urbà, evitant els àmbits monotemàtics, que tan poc afavoreixen la vida urbana i implícitament fomenten la desertització urbana i, per tant, la inseguretat ciutadana quan estan inactius.

La construcció d'aquests traçats s'ha fet en un temps de poc més de 100 anys Això ha permès una gran unitat en l'arquitectura construïda que l'hi atorga en molts casos un gran valor patrimonial, i sovint són objecte de protecció arquitectònica.

Aquest valor patrimonial coincideix amb l'alt valor econòmic del sòl i dels immobles que gaudeix a l'actualitat, essent un dels àmbits amb preus més alts de la ciutat.

La modernitat d'aquesta nova proposta de ciutat del XIX, d'una gran qualitat higiènica, espacial i funcional, ha donat algun dels episodis més brillants de les ciutats estudiades com ara New York, Paris, Viena, Lisboa, Colònia o Barcelona.

Els traçats són encara les millors peces urbanes construïdes en aquestes ciutats, i molt especialment a les del nostre país.

Finalment, cal esmentar que la ciutat projectada des del carrer amb tècniques basades en la reinterpretació de l'alineació té encara un gran recorregut. L'experiència parisenca recent a Bercy, Massena i Tolbiac n'és un exemple excel-lent. 


\section{Bibliografía}

L'Eixample i Cerdà

AA.VV. “Teoria de la construccion de las ciudades. Cerdà y Barcelona. Cerdà y Madrid. Ajunt. Barcelona, MAP. Madrid, 1991

AA.VV. “Treballs sobre Cerdà i el seu Eixample”. LUB, Ajunt. Barcelona, MOPT. Barcelona, 1992.

AA.VV. "La formació de l'Eixample de Barcelona". Aproximació a un fenomen urbà. Olimpíada Cultural B92. Barcelona, 1990.

AA.VV. "Cerdá 1876-1976". Catálogo de la exposición conmemorativa del centenario de su muerte. CICCiP. Barcelona, 1976

AA.VV. "Cerdà. Urbs i Territori, una visió de futur". Ed. Electa i Fundació Catalana per a la Recerca. Barcelona, 1994

AA.VV. "Cerdà i la Barcelona del futur". CCCB. Barcelona, 2009.

Busquets, Joan i altres. "Estudi de l'Eixample". Ajunt. de Barcelona. Barcelona, 1983.

Cerdà, Ildefonso. "Teoría general de la urbanización y aplicación de sus principios y doctrinas a la reforma y ensanche de Barcelona". Instituto de Estudios Fiscales. Madrid, 1968

Corominas, Miquel. "Los orígenes del Ensanche de Barcelona. Suelo, técnica e iniciativa". Ed. UPC Barcelona, 2002.

Grau, Ramon i altres. "Cerdà i els altres. La modernitat a Barcelona, 1854-1874". Ajunt. de Barcelona. Barcelona, 2009.

Estapé, Fabián. "Vida y obra de Ildefonso Cerdà", tomo III de Teoría general de la urbanización y aplicación de sus principios y doctrinas a la reforma y ensanche de Barcelona. Instituto de Estudios Fiscales. Madrid, 1968

Solà-Morales, Manuel de. "Cerdà/Ensanche”. LUB, ETSAB, UPC. Barcelona, 2010.

Soria y Puig, Arturo. "Cerdà. Las 5 bases de la teoría general de la urbanización”. Ed. Electa, Madrid 1996.

\section{Altres}

AA.VV. "La Gran Vía de Zaragoza y otras grandes vías". MV. Madrid, 2011.

Aguilera, Javier i Moreno, Luis. “Urbanismo español en América”. EN. Madrid, 1973.

Alphand, Adolphe. "Les promenades de Paris". J.Rothschild. Paris, 1867-1873.

Aymonino, Carlo; Fabbri, Gianni i Villa, Angelo. "Le città capitali del XIX secolo (I)". Paris e Viena. Officina. Roma, 1975

Ballon, Hilary. "The greatest grid: the Master Plan of Manhattan 1811-2011". NYCM, 2011.

Belski, M. P. "1860-1918 Milano Cresce". Milano: Firenze Libri. 1995.

Busquets, J. "Cities X Lines". Harvard University. Cambridge, 2006.
Cars, Jean des i Pinon, Pierre. "Paris·Haussmann". Picard. Paris, 1991.

França, José-Augusto. "Lisboa: Urbanismo e Arquitectura”. Livros Horizonte. Lisboa, 2005 (5a Ed.) Garcia Espuche, A. "Ciudades: del globo al satélite". CCCB i Electa Ed. Barcelona, 1994. Hall, Thomas. "Planning Europe's Capital Cities". Routledge. 2010. (1ª Ed 1997).

Hills, J. (Cartographer). "City of Philadelphia”. 1796.

Lipsky, F.. "La grille sur les collines". Ed. Parenthèses. Marseilla, 1999

Montaner, J. Mํ. Escaleras, patios, despensas y alcobas. Un análisis de la evolución de la casa artesana a a la de vecinos en Barcelona. Arquitecturas bis n 51, 1985 .

Monteys, X. "La ciutat, la cantonada i la casa. Quaderns d’Arquitectura ํำ255, 2007.

Paricio, A. Secrets d'un sistema constructiu. L'Eixample. Ed. UPC. Barcelona, 2001 i 2008.

Piccinato, Giorgio. "La costruzione dell'urbanistica. Germania 1871-1941”. Officina. Roma, 1974.

Reps, J.W. "The Making of Urban America". Princeton UP. New Jersey, 1965.

Rowe, P. G. "Making a Middle Landscape". Cambridge, Mass.: MIT Press. 1991.

Sabatè, J. "El proyecto de la calle sin nombre". Caja de Arquitectos. Barcelona, 1999.

Solà-Morales, Manuel de. "10 lliçons sobre Barcelona". LUB, COAC. Barcelona, 2008.

Sousa Morais, Joao i Roseta, Filipa. "Os planos da avenida da Liberdade e seu prolongamento". Livros Horizonte. Lisboa, 2005.

Sübben, Joseph. "Der Städtebau”. Arnold Bergstrasser. Darmstadt, 1890.

Vila, Jorge "La casa original del Ensanche de Barcelona, 1860-1864". Tesi doctoral inédita. Departament d'Urbanisme. Biblioteca ETSAB. Barcelona 1989.
Miquel Corominas Ayala, Dr. Arquitecto Profesor del programa de Doctorado en urbanismo Departament d'Urbanisme i Ordenació del Territori · Universitat Politècnica de Catalunya 